\title{
Price Discovery in Currency Markets
}

\author{
Carol L. Osler, Brandeis University, USA* \\ Alexander Mende, RPM Risk \& Portfolio Management AB, Stockholm, Sweden, and Leibniz Universität \\ Hannover, Germany \\ Lukas Menkhoff, Leibniz Universität Hannover, Germany
}

\begin{abstract}
This paper examines the price discovery process in currency markets, basing its analysis on the pivotal distinction between the customer (end-user) market and the interdealer market. It first provides evidence that the price discovery process cannot be based on adverse selection between dealers and end users, as postulated in standard equity-market models, because the spreads dealers quote to their customers are not positively related to a trade's likely information content. The paper then highlights three hypotheses from the literature - fixed operating costs, market power, and strategic dealing - that may explain the cross-sectional variation in customers spreads. The paper finishes by proposing a price discovery process relevant to liquid two-tier markets and providing preliminary evidence that this process applies to currencies. [JEL F31, G14, G15. Keywords: Bid-ask spreads, foreign exchange, asymmetric information, microstructure, price discovery, interdealer, inventory, market order, limit order]
\end{abstract}

June, 2010

Corresponding author: Carol Osler, cosler@brandeis.edu or Brandeis International Business School, Brandeis University, Mailstop 32, Waltham, MA 02454, USA. Tel. (781) 736-4826. Fax (781) 736-2269. We are deeply grateful to the bankers who provided the data and to William Clyde, Pete Eggleston, Keith Henthorn, Valerie Krauss, Peter Nielsen, Peter Tordo, and other bankers who discussed dealing with us. Special thanks go to Clyde, Eggleston, and Tordo, for reading and commenting on drafts of the paper. We thank, without implicating, Geir Bjønnes, Alain Chaboud, Yin-Wong Cheung, Thomas Gehrig, Michael Goldstein, Joel Hasbrouck, Rich Lyons, Albert Menkveld, Bruce Mizrach, Anthony Neuberger, Paolo Pasquariello, Tarun Ramadorai, Dagfinn Rime, Erik Theissen, Dan Weaver, and participants at the European Finance Association Annual Conference in Zurich, the Second Annual Microstructure Conference in Ottawa and at the NBER microstructure meeting for insightful comments. 


\section{Price Discovery in CurRency Markets}

This paper examines the price discovery process in currency markets, basing its analysis on the pivotal distinction between the customer (end-user) market and the interdealer market. It first provides evidence that the price discovery process cannot be based on adverse selection, as postulated in standard equitymarket models, because the spreads dealers quote to their customers are not positively related to a trade's likely information content. The paper then highlights three factors highlighted in the literature that may explain the cross-sectional variation in customers spreads: fixed operating costs, transitory market power, and strategic dealing. The paper finishes by proposing an alternative price discovery process for currencies and providing preliminary evidence for that process.

The dominant model of price discovery focuses on adverse selection between end-users of a financial asset and their dealers (Kyle (1985), Glosten and Milgrom (1985)). In a one-tier market, where all trades are between end-users and dealers, dealers rationally protect themselves from their better-informed customers by quoting a spread (Glosten and Milgrom (1985)). Equilibrium bid and ask prices should incorporate the expected information content of each trade and, in consequence, prices move in the direction consistent with the end-users' information.

Most foreign exchange microstructure papers draw on adverse selection as their primary interpretive framework. The relevance of this framework was initially suggested in Lyons (1995), which shows that trade size and interbank spreads were positively related for a particular dealer in 1992 . The implicit adoption of adverse selection else where in the literature is clear in Payne (2003), for example, which estimates a VAR decomposition of interdealer trades and quotes that he interprets, following Hasbrouck (1991), through the lens of adverse selection. Similarly, Marsh and O'Rourke (2005) estimate Easley et al.'s $(1996,1997)$ adverse-selection-based measure of private information on daily customer trade data.

Our first contribution is to provide evidence indicating that the spreads quoted to foreign exchange customers are not driven primarily by dealer efforts to protect themselves from informed customers. Adverse-selection theory predicts that spreads are wider when end-users are most likely informed, such as when they undertake large trades (Glosten and Milgrom (1985), Easley and O'Hara (1987), Glosten 
(1989)). If dealing is not anonymous, spreads should also be wider for customers that are typically informed. Dealers consider their financial customers - hedge funds and other asset managers - to be fairly well informed, on average. They tend to be fairly savvy about the market and many have insights into upcoming exchange-rate returns. By contrast, their commercial customers - firms that participate in international trade - may know little about the market and typically make no effort to anticipate exchange-rate returns. Empirical evidence confirms that financial customers are relatively well informed (Frömmel et al. (2008); Carpenter and Wang (2003)). Adverse-selection theory thus predicts that financial customers pay wider spreads than commercial customers. Using detailed transaction data from a bank in Germany, we estimate three models of spread determination: the Huang and Stoll (1997) model, the Madhavan-Smidt model (1991), and the Glosten and Harris (1988) model. None of the models support the relevance of adverse selection. Customer spreads are not positively related to trade size and are not wider for financial customers.

Our econometric analysis of all three models indicates that customer spreads are widest for the trades least likely to be informed, directly contrary to the prediction of adverse-selection theory. We are not aware of previous evidence showing narrower spreads for relatively informed customer types though a negative relation between trade size and spreads has been documented for the London Stock Exchange (Bernhardt et al. (2005)) and the U.S. municipal bond market (Green et al. (2007), Harris and Piwowar (2004)). Our second contribution is to analyze the potential determinants of this pattern of customer spreads. The literature highlights at least three factors that could drive this pattern. The first, fixed operating costs, can explain the negative relation between trade size and customer spreads but cannot explain variation across customer types. The second is transitory "market power" dealers gain from their information about current market conditions (Green et al. (2004)). It can be costly for customers to seek out the best quotes, so an individual dealer has market power during the moment of communicating with the customer, even in a market with hundreds of competitors. In foreign exchange, this suggests that dealers extract wider spreads from commercial than financial customers, since commercial customers are typically less savvy about the market. 
The literature also suggests that dealers strategically vary spreads to optimize information flow, rather than passively accepting information flow as assumed in adverse-selection models. Building on theoretical results in Leach and Madhavan (1992, 1993) and Naik et al. (1999) as well as empirical evidence that customer order flow does carry information (e.g., Evans and Lyons (2004), Daníelsson et al. (2002)), we suggest that foreign exchange dealers strategically set narrower spreads to informed customers to gain information from which to profit in subsequent interdealer trading.

The paper's third contribution is to outline a process, new to the literature, through which information may ultimately become embedded in exchange rates. Our proposed price-discovery mechanism focuses on dealers' order choice in the interdealer market. After trading with an informed customer, a dealer's information and inventories provide strong incentives to unload their inventory, and possibly to take a speculative position, by placing market orders or otherwise trading aggressively. An informedcustomer purchase thus tends to trigger aggressive buy trades in the interdealer market and higher interdealer exchange rates. In this way the information brought to the market by informed customers generates information-consistent changes in interdealer prices. By contrast, after trading with uninformed customers a dealer has only weak incentives to place market orders. In short, dealer transactions with uninformed customers are likely to generate limit orders and to add liquidity rather than to move the market price.

This view of dealer behavior, which follows directly from insights already in the literature (Harris (1998), Foucault (1999), Reiss and Werner (2004)), predicts a number of the key stylized facts in foreign exchange microstructure. First, it predicts the positive relation between interdealer order flow and exchange-rate returns documented in Lyons (1995), Payne (2003), Evans (2002), Evans and Lyons (2002), and Daníelsson et al. (2002), inter alia. If dealers are responding to fundamental information, it also predicts that the relation should be substantially permanent, consistent with evidence presented in Payne (2003), Killeen et al. (2005) and Bjønnes et al. (2005). In addition, our view of dealer behavior predicts the positive relation between exchange rates and financial order flow documented in Evans and Lyons (2004), Bjønnes et al. (2005), and Marsh and O'Rourke (2005). Finally, our view predicts that the response of exchange rates to financial order flow is substantially permanent, consistent with evidence in 
Lyons (2001) and Bjønnes and Rime (2005). We test further implications of our proposed price discovery mechanism, most notably that dealers should be more likely to make aggressive trades after large financial-customer trades than after small commercial-customer trades. The evidence is consistent with the hypothesis.

The paper's microstructure message is directly relevant to the literature on exchange-rate dynamics, which is somewhat analogous to the literature on asset pricing within finance. A critical empirical development in exchange-rate economics has been the recognition that order flow strongly influences returns (Evans and Lyons (2002)). Existing theory shows that order flow matters in part because it carries information (e.g., Evans and Lyons (2002), (2004)), but has not articulated the mechanism through which the customers' information is incorporated into exchange rates. Our proposed price discovery framework helps fill this gap.

Our analysis may also have broader implications within microstructure, since we essentially suggest that the price discovery process in any market depends on the market's structure. Since the familiar adverse-selection process assumes a one-tier market, it may not be relevant in markets like foreign exchange with active interdealer trading. Our proposed price discovery process may, in turn, be relevant to other liquid two-tier markets, such as the U.S. Treasury market and the London Stock Exchange. Evidence already shows that the relation between customer spreads and trade size in those markets fits the pattern we identify for currency markets. The mechanism we outline differs, however, from the one outlined in Dunne et al.'s (2009) discussion of the euro-sovereign bond market. In their model, all trades are the same size and all customers are equally informed, while our analysis focuses on information differences between different types of customers and trades of different sizes. Presumably this difference reflects differences in the importance of asymmetric information across markets.

Our data comprise the entire USD/EUR transaction record of a single dealer at a bank in Germany during four months in 2001. These data have two advantages relative to most other tick-by-tick transactions datasets in foreign exchange: (i) they distinguish between financial and commercial transactions, and (ii) they cover a longer time period. 
Our analysis builds on extensive empirical evidence showing that information asymmetries exist in the foreign exchange market (Evans and Lyons (2005); Rime et al. (2010); Moore and Payne (2009), Phylaktis and Chen (2009); Menkhoff and Schmeling (2010)) and that financial-customer trades carry more information, on average, than commercial-customer trades (Fan and Lyons (2003), Carpenter and Wang (2003); Bjønnes et al. (2008); Frömmel et al. (2008); Menkhoff and Schmeling (2008)). Our data do not distinguish among types of financial customers, however, so we do not address the interesting and closely-related issue of whether hedge funds have more information than other asset managers (Osler and Vandrovych (2009)).

The rest of the paper has four sections and a conclusion. Section I describes the foreign exchange market and our data. Section II shows that customer spreads in foreign exchange do not conform to the predictions of adverse-selection theory. Section III discusses how the observed cross-sectional variation in customer spreads may be explained by fixed operating costs, transitory market power, and strategic dealing. Section IV articulates our proposed price discovery process and presents supporting evidence. Section V concludes.

\section{Foreign EXCHANGE MARKET STRUCTURE AND DATA}

As documented in a recent foreign exchange survey (Bank for International Settlements 2007), roughly two thousand dealers compete for business in spot, forward, swap, and derivative contracts. Dealers can be found in almost every country so trading takes place round the clock, with roughly half of each day's trading accounted for by three major trading centers - Tokyo, London, and New York. Trading is relatively concentrated across currencies: the euro, which we study here, is involved in almost one fifth of all trades. The foreign exchange market - or the "FX" market, as it is called by market participants - is immense: daily trading was last formally estimated at \$3.2 trillion (Bank for International Settlements (2007)). The market is also intensely competitive. Banks compete in terms of spreads and in terms of transaction speed, pricing consistency, trading strategies, electronic products, and the quality of customer relationships (Euromoney (2007)). 
The market has two segments, or tiers. In the customer market, currency end-users or equivalently "customers" trade with dealers in a quote-driven market. In the interdealer market, dealers trade currency with each other. End-users include financial firms such as hedge funds, mutual funds, pension funds, and broker-dealers. They also include firms engaged in international trade, which range from major multinationals to small firms. In contrast to equity markets, where individuals can account for half or more of all trading, the overwhelming majority of currency trades are carried out by institutions. FX customer trades are priced directly off interbank quotes. A salesperson constructs the quote given to a customer from a preliminary quote provided at that moment by an interdealer trader. Those preliminary quotes are in turn anchored on the best bid and offer in the interdealer market. In electronic communication networks (e.g., Currenext, FXAll) the connection between interdealer prices and customer quotes is programmed directly into the pricing algorithm. The spreads quoted to these end users are the focus of Sections II and III.

Interdealer trades typically take place on order-driven exchanges, though there is still some direct interdealer trading in the quote-driven market. The share of the interdealer market has dropped noticeably in recent decades, party due to the increasing dominance of electronic brokerages. Trading is now split almost evenly between the interdealer and customer markets (Bank for International Settlements (2007)). ${ }^{1}$

Our data comprise the complete USD/EUR transaction record of a bank in Germany over the 87 trading days from 11 July 2001 to 9 November 2001. Like all significant FX dealers, the bank offers the full range of FX products, including forwards and derivatives; it serves the full range of customers, including financial as well as commercial customers; and it participates in the interdealer market as both liquidity provider and liquidity demander. While the bank desires anonymity, we can state that the bank was included among the banks rated in Euromoney's annual FX poll for 2007, which places it among the top ten percent of all dealing banks worldwide. Furthermore, in that same poll the bank was among those considered "best" in euro-dollar trading.

For each transaction we have the following information: (1) the date and time; (2) the direction (counterparty buys or sells); (3) the quantity; (4) the transaction price; (5) the type of counterparty - deal-

\footnotetext{
${ }^{1}$ Intraday trading in the major currency pairs is never constrained by supply because banks create deposits. During our sample period foreign exchange dealers were effectively the only intraday suppliers of liquidity so there is no need to consider "latent liquidity" (Chacko et al. (2006)).
} 
ing bank, financial customer, commercial customer, preferred customer; (6) the initiator; and (7) the forward points if applicable. We infer the dealer's inventory by cumulating the entire set of successive transactions. Our analysis relies on transaction time, rather than clock time, and all trades are entered in a strict chronological order. The data technically refer to the overall bank, but they are an accurate reflection of a single dealer's behavior because only one dealer was responsible for the bank's USD/EUR trading in spot and forward markets.

Table I provides basic descriptive statistics. ${ }^{2}$ The data include over 3,600 trades worth around $€ 4.3$ billion in aggregate. The mean trade size is $€ 1.2$ million; the average financial-customer trade, at $€ 2.4$ million, is bigger than the average commercial-customer trade, at $€ 0.8$ million. Figure 1 shows the distribution of trades across the trading day. Financial-customer trades (Figure 1A) tend to cluster in the morning, dropping before lunchtime, while commercial-customer trades (Figure 1B) rise steadily during the morning, crest around lunchtime (when they also take a brief, sharp dip), and then decline steadily during the afternoon.

We include outright forward trades adjusted to a spot-comparable basis by the forward points. This is appropriate, given the institutional structure of forward trading: the customer and the dealing bank first agree on a spot trade in exactly the same manner, and with exactly the same incentives, as they would for regular spot trades. When they later adjust the trade to the appropriate maturity, the associated "forward points" are governed by market- and central-bank determined interest differentials so the bank's own influence on the forward price comes almost entirely through the spot quotes. We exclude trades with "preferred customers," typically commercial customers with multi-dimensional relationships with the bank, because these customers' spreads may reflect cross-selling arrangements and because their trades are typically tiny (average size EUR 0.18 million). We also exclude the few transactions over $\$ 25$ million, since such trades essentially represent a distinct market: customers hire dealers to manage such trades. ${ }^{3}$

Table II provides information with which to compare our currency dealer with others described in the literature. In terms of his daily trading value, average transactions per day, and mean absolute price

\footnotetext{
${ }^{2}$ We exclude a few trades with tiny volumes (less than EUR 1,000) or with apparent typographical errors.

${ }^{3}$ Fewer than ten of the customer trades in our sample exceeded $\$ 25$ million. These trades were not excluded when calculating inventory levels.
} 
change between transactions, our dealer is comparable to a NOK/DEM dealer at the large dealing bank examined in Bjønnes and Rime (2005), and more generally our dealer was about average sized for the time (Bank for International Settlements (2002)).

Like all FX dealers, our dealer manages his own inventory (subject to position limits), and quickly eliminate inventory accumulated via customer trades. To evaluate the speed with which our dealer eliminates inventory we estimate the following standard regression:

$$
I_{t}-I_{t-1}=\omega+\rho I_{t-1}+\varepsilon_{t},
$$

where time subscripts correspond to transaction time and we include all 3,534 transactions. If the dealer instantly eliminates unwanted inventories then $\rho \approx-1$; if he makes no effort to manage inventory then $\rho \approx$ 0 . We use GMM with a Newey-West weighting matrix to estimate standard errors that are robust to heteroskedasticity and autocorrelation. The point estimate of $\rho=-0.022$ (standard error 0.007 ) implies a median inventory half-life around two hours, well below estimated inventory reversion speeds for equities which are measured in days (Madhavan and Smidt (1993)) or weeks (Hasbrouck and Sofianos (1993)). If we apply a common alternative approach to measuring FX inventory positions, in which inventories are reset to zero nightly (e.g., Lyons (2001)), median inventory half-life is only 17 minutes.

Our dealer's customers also behave consistently with those analyzed elsewhere in the literature, Cumulative financial- and commercial-customer order flow are both $I(1)$, like the exchange rate itself. ${ }^{4}$ In addition, as shown in Table III, cumulative financial-customer (commercial-customer) order flow is positively (negatively) cointegrated with the exchange rate. Qualitatively consistent results are reported in three studies of large banks - Lyons (2001), Evans and Lyons (2004), and Marsh and O’Rourke (2005) as well as a study based on market-wide data for the Swedish krone (Bjønnes et al. (2005)). This pattern is generally interpreted to mean that net commercial customers often respond to price changes induced by financial-customer liquidity demand (Bjønnes et al. (2005), Osler (2008)). In effect, since dealers generally end the day with close to zero inventory, the exchange rate must move to induce commercial customers to supply overnight liquidity to financial customers.

\footnotetext{
${ }^{4}$ Results suppressed to save space.
} 
Our main qualitative conclusions should generalize beyond this one dealer because FX is an intensely competitive market: during our sample period the largest dealer had market share of only about 10 percent. In FX, the product is liquidity and the price is the bid-ask spread. Dealers confirm their limited influence over spreads when they claim, in surveys, that their primary consideration is the spreads' "conventional level" (Cheung and Chinn (2001)).

Our sample period includes September 11, 2001, but that day's events do not materially affect our conclusions. Despite the extreme disruption of U.S. money, bond, and stock markets, the FX market functioned smoothly overall. Volatility, trading volume, and spreads were high on September 11, 2001 itself, as would be expected in an efficient market subject to major news shocks. But volatility and spreads were indistinguishable from their normal levels by the next day (Mende (2006)). This resilience no doubt stems in part from the large number of dealers and their wide geographical dispersion. In addition, Reuters and EBS, the two major electronic brokerages, both have servers in multiple locations around the world performing real-time replication of all functions.

\section{The Cross-Sectional Pattern of Currency Spreads}

This section evaluates whether the cross-sectional pattern of customer spreads in FX is consistent with the predictions of adverse selection. The first of these predictions, that large trades will be quoted relatively wide spreads, is based on the familiar conclusion that the size of informed trades should vary positively with the likely magnitude of the traders' anticipated price move (Glosten and Milgrom (1985), Easley and O'Hara (1987), Glosten (1989)). Consistent with this, dealers observe that small trades are typically less informative than large trades. For example, William Clyde, formerly a trading-floor manager at First Chicago, found that, "Small trades, no matter what the source, do not contain much information" (personal communication, August 18, 2004).

The second prediction of adverse selection is that financial customers will be quoted wider spreads than commercial customers. Dealers claim that, on average, commercial order flow carries less fundamental information than financial order flow. According to Clyde: 
Financial customers tend to get better spreads because their trades reflect their view of the market, and their views are often shared with other asset managers. ... With corporates you're just seeing their core business activities - car building or whatever. Almost all of them will tell you "we're not in the business of speculating."

Empirical support for the claim that financial customers are better informed is presented in Carpenter and Wang (2003), which finds that dealers widen their spreads after transactions with financial customers but leave spreads unchanged after transactions with commercial customers. This may seem counterintuitive if one envisages commercial-firm trades as dominated by capital issues or a market-sensitive hedging strategy. But the vast majority of commercial trades have no connection to capital events, reflecting instead mundane real-side concerns like a firm's need to import inputs, and hedging strategies are typically revised at most a few times yearly.

Support for this claim also comes from Osler and Vandrovych (2009), who examine the information content of price-contingent trades from different customer types. They find that hedge-fund trades carry information but there is no information in the trades of institutional asset managers, broker dealers, large and middle market corporations, and governments. Fan and Lyons (2003) suggest that financialcustomer order flow carries information relevant to high-frequency exchange-rate dynamics while nonfinancial order flow is more strongly related to multi-year dynamics. As dealers tell us in surveys, they only care about the short-run information (Gehrig and Menkhoff (2004), Oberlechner (2004)), a claim that fits their tendency to carry zero inventory overnight. Additional evidence that financial-customer trades provide information about short-run exchange rates is provided in Froot and Ramadorai (2005).

We estimate three familiar models of spreads: the Huang and Stoll model (1997), the Madhavan and Smidt model (1991), and the Glosten and Harris model (1988), all of which extract measures of spreads from successive price changes. In a simple market where the spread is constant across time and across customers, if the equilibrium price is stable prices only change when they switch from bid to ask or vice versa so the spread can be estimated from price changes. In the absence of price stability, the same conclusion still applies so long as there is no dominant trend. 


\section{A. The Huang and Stoll Model}

Huang and Stoll (1997) observe that trade size is relatively unimportant for pricing in markets like the FX interbank market - where large trades are routinely broken up into multiple smaller transactions. Even in such markets, however, the risk of trading with a better informed counterparty remains. Huang and Stoll's model of a standard competitive dealership market analyzes the pricing decision of a representative dealer whose counterparties have private information that is revealed by their trade direction (buy or sell). Agents are fully rational. The model assumes that dealer $i$ 's quote is determined by the dealer's expected true value of the asset, $\mu_{i t}$, the trade's direction, and the dealer's existing inventory:

$$
P_{i t}=\mu_{i t}+\frac{S}{2} D_{t}-\theta \frac{S}{2}\left(I_{i t}-I_{t}^{*}\right)+v_{t}
$$

The baseline half-spread - meaning the spread that would apply before adjustment for existing inventories - is $S / 2 . D_{t}$ is the direction of trade $\left[D_{t} \equiv 1(-1)\right.$ if the counterparty is a buyer (seller)]. $I_{i t}$ is dealer $i$ 's inventory at the beginning of period $t ; I^{*}$ is his desired inventory. The model permits dealers to manage existing inventories by shading prices to customers (e.g., quoting lower prices when inventory is high), which implies $\theta>0$. The term $v_{t}$ is a mean-zero random disturbance.

Dealer $i$ updates his expectation of the asset's fundamental value in light of the private information revealed by the direction of the previous trade as well as public news, $\varepsilon_{t}: \mu_{i t}-\mu_{i t-1}=(\lambda S / 2) D_{t-1}+\varepsilon_{t}$. The term $\lambda S / 2$ captures the information effect of trade direction and is a direct manifestation of adverse selection. The public news shock, $\varepsilon_{t}$, is a serially uncorrelated. Combining the pricing and updating rules gives the following expression for price changes between transactions:

$$
\Delta P_{i t}=\frac{S}{2}\left(D_{t}-D_{t-1}\right)+\lambda \frac{S}{2} D_{t-1}-\theta \frac{S}{2} \Delta I_{i t}+e_{t},
$$

where $e_{t} \equiv \varepsilon_{t}+\Delta v_{t} . \Delta P_{t} \equiv P_{t}-P_{t-1}$ is measured in pips, which are roughly equivalent to basis points. ${ }^{5}$

Estimation: Our dependent variable is the sequence of prices on transactions initiated by customers, so our econometric analysis once again operates on transaction time rather than clock time. We include

\footnotetext{
${ }^{5}$ A pip is equivalent to a tick: one unit of the smallest significant digit in an exchange rate as conventionally quoted. In the euro-dollar market, where the exchange rate averaged $\$ 1.1128 / €$ during our sample period; a one-pip change from that level would bring the rate to $\$ 1.1129 / €$.
} 
almost all trades by all customers. We follow standard practice and use generalized method of moments (GMM) with a Newey-West weighting matrix that corrects covariance estimates for potential heteroskedasticity and autocorrelation in the residuals (e.g., Yao (1998), Bjønnes and Rime (2005)).

We follow Huang and Stoll (1997) in estimating separate coefficients for trades in various size and customer-type categories, which we achieve by interacting the key right-hand-side variables with dummies for transaction size $\{S m, M d, L g\}$ and counterparty type $\{F C, C C\}$. Dealers report that they informally divide normal-sized customer transactions into three categories: regular trades, which vary from $€ 1$ million to about $€ 25$ million; modest trades; and tiny trades. Though the line between the latter two categories is ambiguous, their treatment can vary substantially: tiny trades are often spread by formula rather than by dealers' discretion and on such trades a one percent spread is not considered unreasonable. We therefore assign the following size ranges: small trades: $\left\{\left|Q_{t}\right| \in(€ 0, € 0.5\right.$ million $\left.)\right\}$; large trades: $\left\{\left|Q_{t}\right| \in\right.$ [€1 million, $€ 25$ million) $\}$; and medium trades: $\left\{\left|Q_{t}\right| \in[€ 0.5\right.$ million, $€ 1$ million $\left.)\right\}$. Table IV provides descriptive statistics on the key variables, specifically trade sizes, returns, inventory, and order flow disaggregated by customer type.

According to correspondents at large dealing banks, the correct customer disaggregation is between small commercial customers, on the one hand, and financial customers and large multinational (commercial) corporations, on the other. Though we cannot technically distinguish large multinationals from other commercial customers, large multinationals are unlikely to do much business with this bank. Thus the counterparty-based tiering identified here should be roughly accurate in the present context.

The results of estimating the Huang and Stoll (1997) model, shown in Table V, provide no support for the implications of adverse selection. Adverse selection would imply that baseline half-spreads are positively related to trade size, but the opposite appears to hold: estimated baseline half-spreads for financial customers are 10.8 pips for small trades, 5.4 pips for medium-sized trades, and 3.4 pips for large trades. Chi-squared statistics from the associated Wald tests highlight that spreads do indeed vary inversely with trade size: for the small-vs.-medium comparison the test statistic is 4.06 with marginal significance 0.044; for the small-vs.-large comparison the test statistic is 6.10 with marginal significance 0.014 . For commercial customers, estimated baseline half-spreads are 13.5 pips for small trades, 11.2 pips for 
medium-sized trades, and 2.1 pips for large trades, and the inverse relation between trade size and spreads is again confirmed statistically. Chi-squared statistic from the Wald test for the small-vs.-large comparison is 46.1 with marginal significance 0.000 ; for the medium-vs.-large comparison the test statistic is 8.81 with marginal significance 0.003 .

Adverse selection would also imply that financial customers are quoted wider spreads than commercial customers. The point estimates for baseline half-spreads provide no evidence to support this implication, either. Indeed, commercial customers are quoted wider spreads for both small and medium trades and the difference is statistically significant for the medium-sized trades (Chi-squared statistic of 4.01 has marginal significance of 0.045). For large trades the estimated baseline half-spread is insignificant for both customer types.

Adverse selection also fails to get support from the estimated adverse-selection coefficients, $\lambda$. Adverse selection theory predicts a positive relation between this parameter and information content but the point estimates imply the opposite for commercial traders. Further, though large financial trades are considered most informed, the one significant value of $\lambda$ applies to medium-sized commercial trades. Finally, adverse selection gets no support from the coefficients on the quantity traded, which should be positive under the theory. This hypothesis is readily rejected by the chi-squared statistic for the exclusion of these six coefficients, 9.746 (marginal significance 0.14 ).

The results of the Huang and Stoll (1997) model also suggest that inventory levels are not relevant to FX customer spreads, since none of the six inventory coefficients is significant. Formal exclusion tests confirm that inventories are not significant (chi-squared statistic is 3.64 with marginal significance 0.72 ). Similar results have been found for other banks examined in the literature, which has led to a broad consensus that FX dealers prefer managing inventory via interbank trades rather than by shading prices to customers (Bjønnes and Rime (2005)).

Table V presents three further robustness tests, all of which support the qualitative conclusions outlined above. In the first we rerun the regression with inventories calculated as in Lyons (2001), where the start value is reset to zero every day. In the second regression we include interdealer as well as customer trades to provide comparability with Bjønnes and Rime (2005), where customer transactions (as a single 
category) and interbank transactions are included in the main regressions. Reassuringly, our bank's baseline half-spread for normal-sized interbank transactions, 2.1 pips, is similar to those estimated for other banks; for example, Goodhart et al. (2002) finds an average spread of 2.8 pips for USD/EUR interbank transactions. In the third robustness test we include spot transactions, which also facilitates comparisons with earlier papers.

Our conclusion that adverse selection does not dominate the determination of customer spreads in the FX market is also robust to the following additional unreported methodological modifications: excluding data for September 11, 2001; using a different cutoff to distinguish between small and medium trades (€300,000 rather than $€ 500,000$ ); and including additional lags of the dependent variable, with lag length of two suggested consistently by the Akaike information criterion and other standard tests.

\section{B. The Madhavan and Smidt Model}

FX dealers consistently report that they consider large customer trades to be more informative than small ones, so the Huang and Stoll (1997) model's assumption that trade size is uninformative may be inappropriate. Trade size is informative in the Madhavan and Smidt model (1991), which has frequently been applied in FX microstructure research (see, for example, Lyons (1995) and Bjønnes and Rime (2005)). In this model, agent $j$ calls dealer $i$ requesting a quote and chooses an amount $Q_{j t}$ that is positively related to the gap between his expected value of the asset, $\mu_{j t}$, and the price quoted by the dealer:

$Q_{j t}=\xi\left(\mu_{j t}-P_{i t}\right)+X_{j t}$, where $\xi>0 . X_{j t}$ represents agent $j$ 's liquidity demand. In setting his regret-free price, $P_{i t}$, dealer $i$ considers his own expected value of the asset, $\mu_{j t}$, his inventory, and the direction of the trade: $P_{i t}=\mu_{i t}+\zeta\left(I_{i t}-I_{i}^{*}\right)+\chi D_{t}$. In determining $\mu_{j}$, dealer $i$ rationally considers customer's desired trade size. If the dealer shades prices to manage existing inventories, $\zeta<0$.

After solving for conditional expectations and taking first differences, one arrives at the following expression for the price change between dealer $i$ 's incoming transactions:

$$
\Delta P_{i t}=\alpha+\beta_{1} D_{t}+\beta_{2} D_{t-1}+\gamma_{1} I_{i t}+\gamma_{2} I_{i t-1}+\delta Q_{j t}+\eta_{t}
$$


The intercept, $\alpha$, should be zero if the dealer's desired inventory is zero. If the dealer shades prices in response to inventories then $\gamma_{2}>\left|\gamma_{1}\right|>0>\gamma_{1}$. Our estimates of the Huang and Stoll model suggest that both $\gamma_{1}$ and $\gamma_{2}$ will be about zero.

Adverse selection, if operative, could influence three parameters in this model. First, it could influence $\beta_{2}$, the coefficient on lagged direction, which according to the model is the negative of the baseline half-spread. Under adverse selection this would be bigger (in absolute value) for large trades and for financial-customer trades. This same effect could also be reflected in $\delta$, the coefficient on trade size: under adverse selection this coefficient should be positive. Large trades can reflect a big gap between the asset's true value and the dealer's quote, so a rational dealer in the model increases the spread with trade size. Unfortunately, the interpretation of a positive coefficient on trade size is inherently ambiguous, since it is observationally equivalent to an inventory effect highlighted in Ho and Stoll (1981): Larger trades leave dealers with higher inventory and greater inventory risk, so larger trades should carry wider spreads.

Finally, adverse selection should influence the relation between $\beta_{1}$ and $\beta_{2}$. The model implies that $\beta_{1}=\left|\beta_{2}\right| / \phi>0>\beta_{2}$, where $0<\phi<1$ is a model-derived parameter capturing the extent to which dealers rely on their priors rather than the current trade in updating their estimate of the currency's true value. Under adverse selection, estimates of $\phi$ should be farther below unity for large trades and for financial trades, since dealers consider such trades to be relatively informative.

As before, we estimate the model using generalized method of moments (GMM) with Newey-West correction for heteroskedasticity and autocorrelation and we interact the key variables with dummies corresponding to trade size and counterparty type. ${ }^{6}$ The results of this analysis, presented in Table VI, tell the same story as the Huang and Stoll (1997) regressions. The estimated baseline half-spreads do not vary positively with the likely information content of each trade as predicted by adverse selection theory. For financial customers, the estimated baseline half-spreads are a statistically-significant 8.9 pips on small trades and roughly one-third that size - and insignificantly different from zero - for medium and large

\footnotetext{
${ }^{6}$ Co-linearity among our instruments is unlikely to be a problem, since the only pair of instruments with non-trivial correlation is Fin $\times Q_{t}$ and Fin $\times L G \times D_{t}$, and the qualitative conclusions from our baseline analysis are sustained when quantity variables are excluded.
} 
trades. Commercial customer half-spreads are estimated to be 13.2 pips on small trades, 5.7 pips for medium trades, and essentially zero for large trades. In this regression the small-vs.-large distinction for financial customers and all size distinctions for commercial customers are statistically significant but differences across counterparty types are not; the counterparty differences become significant, however, when we exclude the inventory and quantity variables which are jointly insignificant as discussed below. ${ }^{7}$

The other two potential sources of evidence for adverse selection are equally unsupportive. The theory implies that the coefficient on trade size, $\delta$, should be positive, but it is only positive for commercial customers and it is statistically insignificant for both customer types. Theory also implies that the ratio between the coefficients on lagged and current direction, $\phi=\left|\beta_{2}\right| / \beta_{1}$, should vary negatively with trade size. Instead this ratio varies non-monotonically with trade size for the financial customers, the customers to which the theory most likely applies: for small, medium, and large financial trades the point estimates are $0.67,0.99$, and 0.66 , respectively. Similarly, though adverse selection predicts smaller values of $\phi$ for financial than commercial customers, the estimates of $\phi$ for medium and large commercialcustomer trades are both below corresponding estimates for financial customers.

The other results from this model are unsurprising. The constant term is insignificant, implying that our dealer's preferred inventory level is indeed about zero. The chi-squared test for the exclusion of inventories and the trade quantity is 3.36 with marginal significance 0.34 , indicating that inventories and the trade quantity itself are jointly insignificant, consistent with our previous results. The results are robust to the following modifications to our baseline methodology, the first three of which are reported in Table VI: calculating inventories with a daily starting value of zero; including interbank trades; excluding forward transactions; excluding September 11, 2001; including two lags of the dependent variable as suggested by the Aikake information criterion; or splitting small and medium trades at $€ 300,000$ rather than $€ 500,000$.

\section{The Glosten and Harris Model}

Glosten and Harris (1988) postulate a model in which inventories play no role; since the inventory coefficients have consistently been insignificant, this may be appropriate. Otherwise the Glosten-Harris

\footnotetext{
${ }^{7}$ Results available upon request.
} 
model is similar to the Madhavan-Shmidt (1991) model except that trade size influences the baseline spread as well as the adverse-selection component. The price set by a market-maker is $P_{i t}=\mu_{i t}+\left(c_{0}+\right.$ $\left.c_{1} V_{t}\right) D_{t}$, where $V_{t}$ is the (absolute value of the) quantity traded and $\left(c_{0}+c_{1} V_{t}\right)$ is the baseline half-spread. The expected value of the asset is the previous period's expected value of the asset adjusted for the size of the customer's desired trade, which captures adverse selection, and by public news: $\mu_{i t}=\mu_{i t-1}+z D_{t} V_{t}+\varepsilon_{t \cdot}{ }^{8}$ The period- $t$ price change is:

$$
\Delta P_{t}=c_{0}\left(D_{t}-D_{t-1}\right)+c_{1}\left(D_{t} V_{t}-D_{t-1} V_{t-1}\right)+z D_{t} V_{t}+\varepsilon_{t}
$$

The term $c_{0}$ should capture fixed effects associated with trading, while the term $c_{1}$ should capture any relation between trade size and spreads that is not associated with adverse selection. The term $z$ should be positive if it captures adverse selection effects as implied by the model.

The results of this analysis, shown in Table VII, provide no more support for adverse-selection than our previous results. The adverse-selection coefficients are consistently insignificant and the hypothesis that they are jointly insignificant is not rejected (F-statistic 1.18, marginal significance 0.31 ). In addition, the baseline spreads for commercial customers are significantly larger than those for financial customers. Indeed, while we can reject the hypothesis that the two coefficients are the same (F-statistic 18.64, marginal significance 0.00 ), we cannot reject the hypothesis that the commercial-customer coefficient is twice the financial-customer coefficient (F-statistic 0.05, marginal significance 0.42 ). This is inconsistent with adverse-selection theory since financial customers are considered better informed, but it confirms our earlier findings. The results also confirm our earlier empirical finding that trade size and baseline spreads are inversely related: the estimated values of $c_{1}$ are negative and significant for both commercial and financial customers. When, as before, we re-run the regressions including interbank trades or excluding forward trades, our qualitative conclusions are sustained.

\footnotetext{
${ }^{8}$ We estimate the more general version of the two estimated by Glosten and Harris (their Equation 6). Note also that since the tick-size in foreign exchange is extremely small (less than 1 basis point), we incorporate rounding errors into the disturbance.
} 


\section{Discussion}

This section has provided evidence that price discovery in FX does not follow the standard adverse selection model. Dealers do not appear to adjust customer spreads to protect themselves against the likely information content of customer trades. Indeed, our analysis suggests a very specific pattern for the crosssectional pattern of FX customer spreads that is the opposite of that predicted by adverse selection:

spreads are widest for the smallest trades and for the least informed customers. ${ }^{9}$

While our results indicate that adverse selection does not dominate FX customer spreads, they do not prove that adverse selection has zero influence on customer spreads. Note also that these results apply to the customer FX market. Quoted interdealer spreads should be invariant to counterparty type, since most interdealer trades benefit from pre-trade anonymity.

Adverse selection successfully explains the relation between spreads and trade size on the NYSE (see, for example, Harris and Hasbrouck (1996), Bernhardt and Hughson (2002), Peterson and Sirri (2003)). Not only are NYSE spreads wider for larger trades, but some stock brokers pay for order flow from retail (uninformed) customers (Easley et al. (1996)). The theory also works well in explaining the pattern of price discrimination among specialists on the non-anonymous Frankfurt Stock Exchange (Theissen (2003)). There are, however, a number of other markets where adverse selection cannot explain the behavior of customer spreads. A negative relationship between spreads and trade size has been documented in the U.S. corporate bond market (Goldstein et al. (2007)) and the London Stock Exchange (Hansch et al. (1999), Bernhardt et al. (2005)). A negative relationship between trade size and spreads has also been observed in the relatively illiquid U.S. municipal bond market, where spreads average 2.23 percent for small trades and 0.10 percent for large trades (Harris and Piwowar (2004)).

The results in this section do not, unfortunately, point to specific alternative determinants of FX customer spreads beyond adverse selection. Nonetheless, a number of hypotheses have been suggested in the broader microstructure literature that are consistent with the patterns documented above.

\footnotetext{
${ }^{9}$ Spreads on commercial trades have narrowed since 2001 due to the enhanced transparency associated with new electronic communication networks.
} 


\section{Operating Costs, Market Power, and Strategic Dealing}

This section highlights three factors that could drive the pattern of FX customer spreads highlighted above: fixed operating costs, transitory market power, and strategic dealing.

\section{A. Fixed Operating Costs}

Per-unit processing costs become smaller as trade size gets larger, a point stressed by Angel (1996) and Hansch et al. (1999) as a potential source of the inverse relationship between spreads and trade size on the London Stock Exchange. While this also seems likely to help explain the negative relation between spreads and trade size in the FX customer market, it is unlikely to explain the gap between spreads paid by financial and commercial customers. Fixed costs do not vary strongly by customer type and marginal costs are, if anything, higher for asset managers, who often require their trade proceeds to be split among numerous individual funds.

One might wonder whether the difference between financial- and commercial-customer spreads reflects a difference in the timing of the two groups' trades. Though there are differences in the timing of financial and commercial trades, as noted in Section I, interdealer spreads in euro-dollar are fairly constant at low levels throughout our bank's regular trading hours (Ito and Hashimoto (2006)). In consequence, intraday trading patterns cannot predict the observed variation in customer spreads.

The rest of this section highlights two mutually consistent theories of dealing under asymmetric information that might explain why FX spreads vary across counterparty types. One theory suggests that information about current market conditions provides dealers with transitory market power relative to uninformed customers, allowing dealers to charge wider spreads. The other theory suggests that dealers strategically vary spreads across customers in an attempt to gather private information. ${ }^{10}$ These information-based forces are mutually consistent and we hypothesize that they operate simultaneously with fixed operating costs. The theories we highlight in this section do not exhaust the long list of factors dealers consider in setting spreads - though a longer list of theories could exhaust the patience of our readers.

\footnotetext{
${ }^{10}$ Huang and Stoll (1997) propose an explanation for the negative relationship between adverse selection costs and transaction size in equity market spreads but it concerns block trades, which do not exist in foreign exchange.
} 


\section{B. Market Power}

Green et al. (2007) point out that dealership markets are opaque due to the dispersion of trading, so current market conditions - meaning real-time mid-quotes, spreads, volatility and the like - can be hard to ascertain. Asymmetric information about these conditions effectively creates bargaining power. As Angel (1996) describes it, "a dealer knows that an unsophisticated individual ... may have higher search costs per share and is not in a good position to monitor the quality of a broker's execution. The broker has little incentive to spend time negotiating or shopping around for a better deal for a small order. Thus, a dealer may take advantage of this by quoting a wider market..." (p. 4). Duffie et al. (2004) develop this insight and related insights into a formal model and show that bargaining power in dealership markets partly reflects the alternatives to trading immediately, alternatives that are influenced by the costs and benefits of further search.

This "market-power" hypothesis can be applied directly to explain why commercial FX customers pay wider spreads than financial customers. Currencies are traded in dealership markets with dispersed information, and dealers consider commercial customers less sophisticated than financial customers. Commercial firms typically trade currencies in order to purchase imports necessary for production or to liquidate export proceeds. Since the firms' currency transactions are scattered across time and often across currencies, the firms do not hire professional traders. Instead, they assign FX trading to administrators with many other responsibilities. Because they trade infrequently it is difficult for these individuals to gain an intuitive understanding of the market, a difficulty often compounded by lack of real-time market information. Further, these individuals are rarely evaluated on execution quality, so they have no incentive to achieve better spreads. In short, traders at commercial firms perceive high costs to search and low benefits, making them ripe targets for wide spreads.

FX traders at financial firms, who are often professionals, perceive lower costs and greater benefits to search because they have plenty of real-time information and are often evaluated on their execution quality. Financial firms may also gain market power from their tendency to undertake large trades (see Table I). As shown in Bernhardt et al. (2005), customers who regularly trade substantial amounts may receive better spreads as dealers compete for their business. 


\section{Strategic Dealing}

The gap between commercial and financial spreads may also reflect strategic dealing: that is, dealers may adjust their pricing so as to extract private information from customer trades. The importance of gathering information from customers is indicated by the following comments of William Clyde, the former trading-floor manager:

Banks will want to make good quotes on large, potentially information-bearing amounts for two reasons. First, it gets them better access to the current information: in addition to getting the directional information won by being dealt on, the caller will sometimes share a little additional information with the bank. With this information you don't get caught out and you can make better trading decisions. Second, it ensures that institutions with large amounts continue to call whenever they have something going on.

Evidence that the order flow of large currency dealing banks includes information about upcoming highfrequency currency returns is provided in Daníelsson et al. (2002), Evans and Lyons (2006), and Rime et al. (2009). The two-tier structure of FX makes it logical for FX dealers try to capture informative customer order flow, since they can exploit the information in subsequent interdealer trading. ${ }^{11}$ Bjønnes et al. (2008) provides evidence that even the interbank trades of relatively small banks do carry information, on average, though they carry less information than the trades of big banks.

The insight that market makers might strategically manipulate spreads to increase the information value of order flow was originally explored in Leach and Madhavan $(1992,1993)$. Those papers use equity-market inspired models to demonstrate that market makers in one-tier markets may adjust prices early in a trading session to enhance later profitability. Flood et al. (1999) present evidence for this type of strategic dealing in an experimental market similar to the FX interdealer market. Our evidence, however, concerns cross-sectional variation in spreads rather than variation across time. Naik et al. (1999) presents an equity-inspired model of strategic dealing in a two-tier market in which some customers are relatively well informed. They conclude that customer spreads will be narrower for more informed customers, consistent with the pattern we document for FX. Hansch and Neuberger (1997) present evidence consistent with this type of strategic dealing on the London Stock Exchange.

\footnotetext{
${ }^{11}$ Strategic dealing may be more relevant in FX than the municipal or corporate bond markets, since most such bonds trade relatively infrequently so the information value of any trade may be negligible.
} 
Our bank's order flow need not be hugely informative for strategic dealing considerations to influence its customer spreads. Since dealers are largely price takers with respect to spreads (Cheung and Chinn (2001)), strategic dealing will indirectly influence spreads at moderate-sized banks so long as it directly influences spreads at the largest banks. ${ }^{12}$

Evidence for strategic dealing in FX is presented in Ramadorai (2008), who analyzes the transactions of asset managers and finds that spreads are narrower for managers that produce higher (riskadjusted) FX returns. Reitz et al. (2009) provide evidence for the broader claim, implied by both the market power and the strategic dealing hypotheses, that financial customers have more bargaining power than commercial customers vis-à-vis their dealers.

\section{Price Discovery in Foreign Exchange}

The evidence presented here suggests that spreads in the FX customer market are not positively related to a trade's information content, as implied by adverse selection. Indeed, when a customer comes to the market with information the price he pays moves less than it would for an uninformed customer. But if adverse selection is not the basis for price discovery in currency markets, what is? This section proposes an alternative price discovery mechanism for FX and provides evidence consistent with that mechanism. Our proposed mechanism reflects the FX market's two-tiered structure. We hypothesize that price discovery happens in the interbank market but that much, possibly all the market-relevant information is brought to the market by customers.

According to our proposed price discovery mechanism, the sequence through which information moves from customers to market prices involves three stages. In the first stage, dealers trade with customers but information brought to the market by informed customers does not move prices. In the second stage, the information moves prices in the interdealer market when dealers trade with each other, but customer prices remain unaffected. The information finally affects customer prices thereafter when dealers trade with more customers.

\footnotetext{
${ }^{12}$ This pre-occupation with standard practice may bring to mind the issues of collusion on the NASDAQ raised in Christie and Schultz (1994). However, there are literally hundreds of dealers in the major currency pairs, and they are spread across the globe; it seems unlikely that collusion could maintain FX spreads for decades.
} 
Because this mechanism involves many stages, any formalization of it awaits the resolution of technical constraints in the literature. The dynamics of limit-order markets with asymmetric information are so complex that financial models have just begun to yield closed-form solutions. But the complexities of our hypothesis exceed even these, since it involves the interaction of an order-driven (interdealer) market with a quote-driven (customer) market, both under asymmetric information. Fortunately, all the key conceptual elements of our proposed mechanism have been articulated in the literature: our contribution is to articulate a synthesis appropriate for the FX context.

\section{A. The Mechanism}

This section describes in greater detail the three stages of our proposed price discovery mechanism. In stage one, an informed customer contacts his dealer to trade. In Glosten and Milgrom (1985), this customer, like any other, would pay a spread that incorporates the trade's expected information content. Since customer trades are not anonymous, in a Glosten and Milgrom setting the informed customer would pay a relatively wide spread and the trades of informed customers would move the market more, on average, than the trades of uninformed customers. In this way, prices paid in the customer market would immediately reflect their information. Our evidence indicates, however, that for a given market mid-quote informed customers transact at prices that move the market less than those of uninformed customers. This implies, importantly, that a customer's market-relevant information is not immediately and directly impounded in customer prices.

In stage two of our proposed price discovery mechanism, a customer's information influences the interdealer price. The dealer infers some or all of the customer's information and uses that information to guide his own trades. Consider a dealer whose inventory begins at zero and then rises abruptly in response to a customer decision to sell. Interdealer markets are crucially important for inventory management in FX (Lyons (1995)) as in other two-tier markets (Manaster and Mann (1996), Reiss and Werner (1998)). Since FX dealers prefer to have zero inventory, this dealer will most likely try to offload the new inventory to another dealer. As described in Section I, dealers can trade through interdealer brokers or they can trade directly. Our analysis carries through regardless of this choice, as described below. 
Suppose our dealer trades through the brokers, in which case he submits either a market sell or a limit sell. Harris (1998) and Foucault (1999) highlight a central trade-off: market orders provide immediate execution with certainty while limit orders provide better prices but uncertain execution. We argue that this choice will depend on the nature of the customer, since customer trades are not anonymous (Reiss and Werner (1998)), and the size of the trade.

If the customer is considered informed the dealer has three incentives to exploit the immediacy offered by market orders: (i) he has information and might rationally speculate, other things equal; (ii) he has inventory with its inherent risk; and (iii) his information indicates that his inventory could soon bring a loss. Our dealer therefore seems likely to place a market sell order and earn the lower bid price, for an amount that could exceed the new inventory if the dealer chooses to open a speculative position. The dealer's market sell will bring a lower price. The structure of the interdealer market itself matches in critical respects the one analyzed in Glosten and Milgrom (1985), so regret-free interbank prices should reflect the dealer's information.

Suppose instead the customer is uninformed. In this case the dealer has only one incentive to place a market order: the inherent riskiness of his inventory. Our dealer might be more likely to place a limit order which, if executed, would earn him the higher offer price. The limit order would provide liquidity to the market rather than move the price. In short, we suggest that dealers have a stronger tendency to place market orders after informed customer trades than after uninformed customer trades. ${ }^{13}$ The connection to price discovery is direct: brokered interdealer prices will therefore tend to move in the direction indicated by informed trades. ${ }^{14}$

If our dealer chooses to trade in the over-the-counter market, this analysis changes only superficially. Calling another dealer, like placing a market order, produces a quick, certain trade at a relatively undesirable price; waiting for someone else to call, like placing a limit order, could bring a better price but

\footnotetext{
${ }^{13}$ The choice between limit and market orders will also hinge on market conditions, such as the width of the bid-ask spread and the depth of the book (Biais et al. (1995), Goettler et al. (2005), Lo and Sapp (2005)).

${ }^{14}$ Our conclusion that dealers will place outgoing/market orders after trading with informed customers is consistent with the finding of Bloomfield et al. (2005) that informed traders provide liquidity when the value of their information is high (low). In their experimental setting information is most valuable when it is new. In FX markets, information is newest right after a dealer trades with an informed customer, which corresponds to the time we suggest the dealer will place the outgoing/market order.
} 
could instead bring no trade at all. A dealer has strong incentives to call another dealer after buying from an informed customer, in which case he sells at the lower bid price. After trading with an uninformed customer the dealer is more likely to wait for incoming calls and the price is less likely to fall.

We have so far outlined the first two stages of our proposed price discovery mechanism. Events in the third stage, during which market-relevant information influences customer prices, are dictated by the market's institutional structure. Since foreign-exchange customer trades are priced directly off interbank quotes (as outlined in Section I), once the interdealer quotes reflect the new market-relevant information subsequent trades will reflect that information as well. This applies to all customer trades with any dealer.

The price discovery mechanism just outlined could conceivably lead to a no-trade equilibrium in the interdealer market if (i) customer identity were the only factor determining whether a dealer makes an outgoing trade and (ii) customer identity were a reliable indicator of whether the customer is informed at a given point in time. In this case all market orders would be placed by dealers with information, so uninformed dealers would always be at an informational disadvantage when placing limit orders and trading would cease. These conditions do not hold, however. The literature identifies many factors besides information that influence order choice, and these have been shown to influence FX dealers (Menkhoff et al. 2010). Furthermore, customer identity is imperfectly correlated with a customer's private information.

It is helpful to distinguish the price discovery mechanism postulated here from the one outlined in Glosten and Milgrom‘s (1985) sequential trade model. Like the Glosten and Milgrom process, ours incorporates a sequence of individual customer trades of which a subset carries information. But in FX, dealers know each customer's identity and they know which customers tend to be informed. In addition, FX dealers have access to an interbank market. Price discovery in FX thus involves two sequences: the sequence of individual customer trades and the sequence through which each bit of information moves prices in the delaer and customer markets. When an informed FX customer trades with his dealing bank, the customer price does not immediately move to reflect that information, contrary to the Glosten and Milgrom framework, because the dealer quotes informed customers relatively narrow spreads. The customer's information impacts market prices in stage two, when the dealer extracts information from the customer's trade and uses that information in his own trading. The customer's information finally reaches 
the customer market in stage three, when new customer prices throughout the market are based on the new interdealer prices.

\section{B. Explaining the Stylized Facts}

This proposed price discovery mechanism predicts a number of the stylized facts in FX microstructure. For example, it predicts that the relatively-informed financial order flow will be positively related to exchange-rate returns. Evidence for such a relationship is provided in Evans and Lyons (2004), Bjønnes et al. (2005), and Marsh and O'Rourke (2005). If the information in question is fundamental, then our analysis also predicts that this relationship between financial order flow and exchange rates is substantially permanent, evidence for which is provided in Lyons (2001) and in Bjønnes et al. (2008).

This proposed price discovery mechanism also predicts a positive and largely permanent relationship between exchange rates and interdealer order flow. (In the order-driven or brokered portion of the interdealer market order flow is market buy orders minus market sell orders; in the quote-driven or direct dealing portion of that market the initiator is the dealer that calls out.) Consistent with this prediction, substantial evidence indicates a strong and positive contemporaneous correlation between interdealer order flow and exchange-rate returns at the daily and weekly horizons (see Lyons (1995), Evans (2002), Evans and Lyons (2002), Daníelsson et al. (2003), Payne (2003) and Killeen et al. (2005), inter alia). Furthermore, a substantial portion of this relationship is permanent (Evans and Lyons (2002), Payne (2003), Killeen et al. (2005), Bjønnes et al. (2005)).

This proposed price discovery mechanism also answers a natural question regarding the strategic dealing hypothesis: If dealers quote narrower spreads to attract informed customers, how do the dealers benefit from that information? We answer: they benefit via enhanced interdealer trading. The information permits them to reduce their inventory risk and/or to take speculative positions based on the information.

\section{Additional Evidence}

Our proposed price discovery mechanism has four additional testable implications. First, it predicts that interdealer prices are the best measure of "the market" at any instant. Abundant institutional evidence confirms this implication. Most critically, dealers universally base their customer quotes on the interdeal- 
er market's current best bid and offer, as described in Section I. Second, our proposed price discovery mechanism predicts that dealers with the most customers should be best informed and should profit the most from interdealer trading, consistent with the finding in Bjønnes et al. (2008) that large-bank trades have greater predictive power for returns than small-bank trades.

The third and fourth testable implications of our proposed price discovery mechanism concern the likelihood of outgoing interbank transactions. Under our proposed price discovery mechanism, dealers should be more likely to place interdealer market orders after trades with financial customers than after trades with commercial customers. Similarly, dealers should be more likely to place interdealer market orders after larger trades than after small ones, even after controlling for inventory. If our hypothesis is incorrect and information from individual customers is not critical to the dealers' make or take decisions, then customer type and trade size should not matter once we control for the dealer's inventory level and other relevant factors.

We test these last two implications via a probit analysis of the conditional probability that a given transaction is outgoing in the interbank market:

$$
\operatorname{Prob}\left(\text { Trade }_{t}=I B^{\text {out }}\right)=P\left(F C_{t-1}, C C_{t-1}, 10 \text { mio }_{t-1},\left|I_{i t}\right|, I_{i t}^{2},\left|Q_{j t}\right|\right) .
$$

Our hypothesis concerns the first three variables: dummy variables indicating that the previous trade was with a financial customer, $F C_{t-1}$, or with a commercial customer trades, $C C_{t-1}$, and a dummy set to one if the previous transaction was worth $€ 10$ million or more, $10 \mathrm{mio}_{t-1}$. Our conjecture suggests that the coefficient on the financial dummy will be higher than the coefficient on commercial dummy and the coefficient on 10 mio $t-1$ will be positive.

The last three terms in Equation (5a) capture other factors relevant to the decision to place a market order. The coefficient on absolute inventory, $\left|I_{i t}\right|$, would likely be positive since higher inventory brings higher inventory risk. The influence of inventory seems likely to diminish as inventories get larger, so we follow Bjønnes and Rime (2005) by including squared inventory, $I_{i t}{ }^{2}$, to capture potential nonlinearities in this relationship. The absolute size of the current transaction, $\left|Q_{j t}\right|$, is included because our dealer's customer transactions are often smaller than $\$ 1$ million, the minimum size for brokered trades. Since our dealer prefers to carry out interbank trades on EBS, a broker, rather than by dealing directly, he seems 
likely to collect inventory from small customer transactions and then square his position by submitting one relatively substantial market order.

The results of estimating Equations (5a), shown in column one of Table VII, support our view that the likelihood of an outgoing interbank transaction is higher when the previous transaction is considered informed. Outgoing interbank transactions are statistically significantly more likely when the previous transaction involves a financial customer than when it involves a commercial customer. They are also statistically significantly more likely after relatively big trades, meaning those over $€ 10$ million.

The economic magnitudes of these effects can be gauged by calculating the probability of an outgoing interbank trade for different types of previous trades with other variables evaluated at sample means. After a moderate-sized commercial trade the estimated probability of an outgoing interbank transaction is 9.6 percent; after a similarly-sized financial trade that probability is roughly twice as large, at 18.9 percent. After a commercial trade over $€ 10$ million, the probability of an outgoing interbank transaction is 26.3 percent. After a similarly-sized financial trade, this probability reaches 41.6 percent.

Our analysis has the further implication that the likelihood of an aggressive outgoing trade is higher when the direction of the outgoing trade is similar to the direction of the previous incoming trade. For example, if the previous trade was a financial-customer purchase then the likelihood that the dealer responds aggressively is higher if the dealer is also choosing to make a purchase. ${ }^{15}$ To capture this insight we run an expanded version of the regression outlined above, in which dummy variables capture whether the current trade has the same direction as the previous trade. One same-direction dummy applies to financial customers $(S D F C)$ and the other applies to commercial customers $(S D C C)$ :

$$
\operatorname{Prob}\left(\text { Trade }_{t}=I B^{\text {out }}\right)=P\left(F C_{t-1}, C C_{t-1}, S D F C_{t-1}, S D C C_{t-1}, 10 m i o_{t-1},\left|I_{i t}\right|, I_{i t}{ }^{2},\left|Q_{j t}\right|\right) .
$$

The results of this regression, shown in column two of Table VIII, indicate as before that the likelihood that the dealer makes an aggressive interbank trade rises with the likelihood that the previous trade was informed. As expected, they indicate that the likelihood is higher when the current trade is in the same direction as the previous trade, and the economic magnitude of this effect is substantial. After a large commercial trade the likelihood of an outgoing trade more than doubles, rising from to 22 to 56 per-

\footnotetext{
${ }^{15}$ We are grateful to an anonymous referee for pointing out this implication.
} 
cent, if the dealer trades in the same direction; for large financial trades the likelihood also almost doubles, from 32 percent to 77 percent.

In the results from our baseline regressions, the inventory terms are statistically insignificant, though Bjønnes and Rime (2005) find inventories significant in related regressions. This may reflect mismeasurement of the relevant variable, which should be the gap between actual and desired inventory ra-

ther than the level of inventory per se. To better address this issue we use our other measure of inventory, in which each day's starting value is set to zero. This modification leaves our main conclusions unaffected but inventories themselves become statistically significant. As anticipated, they have a positive and concave relation to the likelihood the dealer trades aggressively in the interbank market.

Our proposed mechanism also implies that our dealer should tend to trade more aggressively after incoming trades by other dealers. Existing evidence suggests that our bank is likely to consider other banks to be better informed, on average (Bjønnes et al. (2008)). Banks of all sizes have information, but banks with the most customers are best informed, and our bank has a relatively modest customer base compared with the likes of Citibank and Deutsche Bank. To test whether our bank tends to view other banks as informed we include incoming interbank trades as a determinant of order aggressiveness. The results indicate that our bank trades more aggressively after incoming trades by other dealers than after commercial trades, as expected (Table VIII, column four). Other properties of the regression are unaffected. Our main conclusions are also insensitive to the inclusion of forward trades (Table VIII, column five), and to the exclusion of September 11, 2001 (unreported).

\section{Conclusions}

This paper examines the process of price discovery in FX markets. Our benchmark is the standard model of spread determination in equity markets, in which dealers avoid losses to their informed customers by setting an appropriate bid-ask spread. Spreads in this setting widen with the likelihood that a customer is informed. Using the complete USD/EUR trading record of a bank in Germany over a period of four months, the paper first provides evidence that the spreads quoted to foreign-exchange end users/customers do not behave this way. Instead, the evidence suggests that customer spreads narrow with 
the likelihood that a customer is informed: customer spreads are wider for small trades than for large trades and are wider for the relatively uninformed commercial customers than for financial customers. Other implications of adverse selection are also not supported for this market. We infer that the standard adverse selection model does not adequately describe the price discovery process in FX.

The paper then highlights three hypotheses from the broader microstructure literature that can help explain the pattern of cross-sectional variation in currency spreads. First, since dealers' operating costs are partially fixed it would be natural for spreads to be larger for small trades. The wider spreads paid by commercial customers cannot be explained by operating costs but could be explained in part by Green et al.'s (2007) market-power hypothesis. This asserts that spreads in quote-driven markets vary positively with a dealer's transitory market power relative to a given customer, and that such market power derives in part from knowledge of market conditions. Commercial customers tend to know the least about current market conditions, so this theory predicts they pay the widest spreads, as they do. The customer-based variation in spreads could also reflect dealers' attempts to strategically gather information (Leach and Madhavan (1992), (1993), Naik et al. (1999)). Dealers may narrow spreads to attract informed customers and extract information from their trades, information from which the dealers can benefit in subsequent interdealer trades. Dealers consider financial order flow to be relatively informative, so this theory predicts that financial customers pay the narrowest spreads, as they do.

The final section of the paper proposes a new price discovery process that incorporates the FX market's two-tiered structure. We first note that price discovery must take place in the interdealer market, since customers' information is not embedded in the prices they are quoted. We suggest that after trading with informed customers dealers tend to make parallel outgoing interdealer trades - placing a market buy order after an informed customer buy, for example - in order to eliminate the likely loss-producing inventory and/or to take a speculative position. In this way the information from customer trades becomes reflected in interdealer prices. After trading with uninformed customers, by contrast, dealers will be more likely to place parallel limit orders or to wait for incoming calls, leaving price relatively unaffected.

Our theory predicts some key stylized facts in FX, specifically the positive and substantially permanent relation between cumulative interdealer order flow and exchange rates as well as the positive and 
substantially permanent relation between financial order flow and exchange rates. Our theory also predicts that dealers are more likely to place aggressive interdealer trades after informed customer trades, and we provide evidence consistent with this implication.

Customer spreads are known to vary inversely with trade size in other liquid two-tier markets, including the U.S. Treasury market, the U.S. corporate bond markets, and the London Stock Exchange. Future research could constructively investigate whether the price discovery mechanism proposed here is relevant in these markets. 


\section{REFERENCES}

Angel, James, 1996, Who gets price improvement on the NYSE? Georgetown University Working Paper FINC-1377-12-694.

Bank for International Settlements, 2002, Triennial central bank survey, foreign exchange and derivatives market activity in 2001 (B.I.S., Basel).

Bank for International Settlements, 2007, Preliminary global results, Triennial central bank survey, foreign exchange and derivatives market activity in 2007 (B.I.S., Basel).

Bernhardt, Dan, and Eric Hughson, 2002, Intraday trade in dealership markets, European Economic Review 46, 1697-1732.

Bernhardt, Dan, Vladimir Dvoracek, Eric Hughson, and Ingrid M. Werner, 2005, Why do larger orders receive discounts on the London Stock Exchange? Review of Financial Studies 18, 1343-1368.

Biais, Bruno, Pierre Hillion, and Chester Spatt, 1995, An empirical analysis of the limit order book and the order flow in the Paris Bourse, Journal of Finance 50, 1655-1689.

Bjønnes, Geir Høidal, Carol Osler, and Dagfinn Rime, 2008, Asymmetric information in the interbank foreign exchange market, Norges Bank Working Paper 2008-05.

Bjønnes, Geir Høidal, and Dagfinn Rime, 2005, Dealer behavior and trading systems in foreign exchange markets, Journal of Financial Economics 75, 571-605.

Bjønnes, Geir Høidal, Dagfinn Rime, and Haakon O.Aa. Solheim, 2005, Liquidity provision in the overnight foreign exchange market, Journal of International Money and Finance 24, 175-196.

Bloomfield, Robert, Maureen O'Hara, and Gideon Saar, 2005, The "make or take" decision in an electronic market: Evidence on the evolution of liquidity, Journal of Financial Economics 75, 165199.

Carpenter, A., and J. Wang 2003, Sources of private information in FX trading. Mimeo, University of New South Wales.

Chacko, George, Sriketan Mahanti, Gaurav Mallik, and Marti Subrahmanyam, 2006, The determinants of liquidity in the corporate bond markets: an application of latent liquidity, Working Paper.

Cheung, Yin-Wong, and Menzie D. Chinn, 2001, Currency traders and exchange rate dynamics: a survey of the U.S. market, Journal of International Money and Finance 20, 439-471.

Christie, William G., and Paul H. Schultz, 1994, Why do NASDAQ market makers avoid odd-eighth quotes? Journal of Finance 49, 1813-1840.

Daníelsson, Jon, Richard Payne, and Jinhui Luo, 2002, Exchange rate determination and inter-market order flow effects, Typescript, Financial Markets Group, London School of Economics.

Duffie, Darrell, Nicolae Garleanu, and Lasse Heje Pedersen, 2004, Over-the-counter markets. Econometrica 73: 1815-1847.

Dunne, Peter G., Harald Hau, and Michael Moore, 2009, A tale of two platforms: dealer intermediation in the European sovereign bond market, Working paper, Insead.

Easley, David, and Maureen O'Hara, 1987, Price trade size and information in securities markets, Journal of Financial Economics 19, 69-90.

Easley, David, Nicholas M. Kiefer, and Maureen O'Hara, 1996, Cream skimming or profit sharing? The curious role of purchased order flow, Journal of Finance 51, 811-833. 
Easley, David, Nicholas M. Kiefer, and Maureen O'Hara, 1997, One day in the life of a very common stock, Review of Financial Studies 10, 805-835.

Euromoney, May 2007. Euromoney FX Poll 2007:

http://www.euromoney.com/article.asp?PositionID=polls\&ArticleID=1330478

Evans, Martin, 2002, FX trading and exchange rate dynamics, Journal of Finance 57, 2405-2448.

Evans, Martin D.D., and Richard K. Lyons, 2002, Order flow and exchange rate dynamics, Journal of Political Economy 110, 170-180.

Evans, Martin D.D., and Richard K. Lyons, 2004, Exchange-rate fundamentals and order flow, Mimeo, U.C. Berkeley and Geortown University.

Evans, Martin D. D. and Richard K. Lyons (2005), Meese-Rogoff Redux: Micro-Based Exchange-Rate Forecasting. American Economic Review Papers and Proceedings, 95(2), 405-414.

Evans, Martin D.D., and Richard K. Lyons, 2006, Understanding order flow, International Journal of Finance and Economics 11, 3-23.

Fan, Mintao, and Richard K. Lyons, 2003, Customer trades and extreme events in foreign exchange, in: Paul Mizen (ed.), Monetary history, exchange rates and financial markets: essays in honour of Charles Goodhart (Northampton: Edward Elgar), 160-179.

Flood, Mark D., Ronald Huisman, Kees G. Koedijk, and Ronald J. Mahieu, 1999, Quote disclosure and price discovery in multiple-dealer financial markets, Review of Financial Studies 12, 37-59.

Foucault, Thierry, 1999, Order flow composition and trading costs in a dynamic limit order market, Journal of Financial Markets 2, 99-134.

Frommel, Alexander Mende and Lukas Menkhoff (2008), Order Flows, News, and Exchange Rate Volatility", Journal of International Money and Finance, 27.

Froot, Kenneth A., and Tarun Ramadorai, 2005, Currency returns, intrinsic value, and institutional investor flows, Journal of Finance 60, 1535-1566.

Gehrig, Thomas, and Lukas Menkhoff, 2004, The use of flow analysis in foreign exchange: exploratory evidence, Journal of International Money and Finance 23, 573-594.

Glosten, Lawrence, 1989, Insider trading, liquidity, and the role of the monopolist specialist, Journal of Business 62, 211-235.

Glosten, Lawrence, and Paul Milgrom, 1985, Bid, ask, and transaction prices in a specialist market with heterogeneously informed agents, Journal of Financial Economics 14, 71-100.

Goettler, Ronald, Christine Parlour, and Uday Rajan, 2005, Equilibrium in a dynamic limit order market, Journal of Finance 60, 2149-2192.

Goldstein, Michael A., Edith S. Hotchkiss, and Erik R. Sirri, 2007, Transparency and liquidity: A controlled experiment on corporate bonds, Review of Financial Studies. 20, 235-273.

Goodhart, Charles, Ryan Love, Richard Payne, and Dagfinn Rime, 2002, Analysis of spread in the Dollar/Euro and Deutsche-Mark/Dollar foreign exchange markets, Economic Policy 17:35, 536-552.

Green, Richard C., Burton Hollifield, and Norman Schurhoff, 2007, Financial intermediation and the costs of trading in an opaque market, Review of Financial Studies 20, 275-314.

Hansch, Oliver, and Anthony Neuberger, 1997, Strategic trading by market makers on the London Stock Exchange, Mimeo, London Business School. 
Hansch, Oliver, Narayan Naik, and S. Viswanathan, 1999, Preferencing, internalization, best execution, and dealer profits, Journal of Finance 54, 1799-1828.

Harris, Lawrence, 1998, Optimal dynamic order submission strategies in some stylized trading problems, Financial Markets, Institutions, and Instruments 7, 1-75.

Harris, Lawrence, and Joel Hasbrouck, 1996, Market vs. limit orders: The SuperDOT evidence on order submission strategy, Journal of Financial and Quantitative Analysis 31, 213-231.

Harris, Lawrence E., and Michael S. Piwowar, 2004, Report on transactions in municipal securities, Securities and Exchange Commission.

Hasbrouck, Joel, 1991, Measuring the information content of stock trades, Journal of Finance 46, 179207.

Hasbrouck, Joel, and George Sofianos, 1993, The trades of market makers: An empirical analysis of NYSE specialists, Journal of Finance 48, 1565-1593.

Ho, Thomas S.Y., and Hans R. Stoll, 1981, Optimal dealer pricing under transactions and return uncertainty, Journal of Financial Economics 9, 47-73.

Huang, Roger D., and Hans R. Stoll, 1997, The components of the bid-ask spread: A general approach, Review of Financial Studies 10, 995-1034.

Ito, Takatoshi, and Yuko Hashimoto, 2006, Intraday seasonality in activities of the foreign exchange markets: Evidence from the Electronic Broking System, Journal of Japanese International Economics 20, 637-664.

Killeen, William, Richard K. Lyons, and Michael J. Moore, 2005, Fixed versus flexible: Lessons from EMS order flow, Journal of International Money and Finance 25, 551-579.

Kyle, Albert, 1985, Continuous auctions and insider trading, Econometrica 53, 1315-1335.

Leach, J. Chris, and Ananth N. Madhavan, 1992, Intertemporal price discovery by market makers: Active versus passive learning, Journal of Financial Intermediation 2, 207-235.

Leach, J. Chris, and Ananth N. Madhavan, 1993, Price experimentation and security market structure, Review of Financial Studies 6, 375-404.

Lo, Ingrid, and Stephen G. Sapp, 2005, Price aggressiveness and quantity: How are they determined in a limit order market? Presented at the Norges Bank/Norwegian School of Management Conference on Equity and Currency Market Microstructure, September 2005.

Lyons, Richard K., 1995, Tests of microstructural hypotheses in the foreign exchange market, Journal of Financial Economics 39, 321-351.

Lyons, Richard K., 2001, The microstructure approach to exchange rates (Cambridge: MIT Press).

Madhavan, Ananth N., and Seymour Smidt, 1991, A Bayesian model of intraday specialist pricing, Journal of Financial Economics 30, 99-134.

Madhavan, Ananth N., and Seymour Smidt, 1993, An analysis of changes in specialist inventories and quotations, Journal of Finance 48, 1595-1628.

Manaster, Stevern, and Steven C. Mann, 1996, Life in the pits: Competitive market making and inventory control, Review of Financial Studies 9, 953-975.

Marsh, Ian, and Ceire O'Rourke, 2005, Customer order flow and exchange rate movements: Is there really information content? Presented at the Norges Bank/Norwegian School of Management Conference on Equity and Currency Market Microstructure, September 2005. 
Mende, Alexander, 2006, 09/11 on the USD/EUR exchange market, Applied Financial Economics 16, 213-222.

Menkhoff, Lukas, and Maik Schmeling, 2008, Local information in foreign exchange markets, Journal of International Money and Finance 27, 1383-1406.

Menkhoff, Lukas, Carol Osler, and Maik Schmeling, 2010, Limit-Order Submission Strategies under Asymmetric Information, Journal of Banking and Finance, forthcoming.

Moore, Michael, and Richard Payne, 2009, Size, specialism and the nature of informational advantage in inter-dealer foreign exchange trading, presented at the Fifth Central Bank Workshop on Market Microstructure, Zurich, October 9, 2009.

Naik, Narayan Y., Anthony Neuberger, and S. Viswanathan, 1999, Trade disclosure regulation in markets with negotiated trades, Review of Financial Studies 12, 873-900.

Oberlechner, Thomas, 2004, The Psychology of the Foreign Exchange Market, Wiley.

Osler, Carol, 2008, Foreign exchange microstructure: A survey of the empirical literature, Encyclopedia of Complexity and System Science Robert A. Meyers, Ed (Springer, New York: 2009).

Osler, Carol, and Vitaliy Vandrovych, 2009, Hedge funds and the origins of private information in the foreign exchange market, presented at the Third Annual Microstructure Workshop, Emerging Markets Group, Cass Business School, London, May 1, 2009.

Payne, Richard, 2003, Informed trade in spot foreign exchange markets: an empirical investigation, Journal of International Economics 61, 307-329.

Phylaktis, Kate, and Long Chen, 2009, Asymmetric information, price discovery, and macroeconomic announcements in fx market: do top trading banks know more? International Journal of Finance and Economics, forthcoming.

Peterson, Mark A., and Erik R. Sirri, 2003, Order preferencing and market quality on U.S. equity exchanges, Review of Financial Studies 16, 385-415.

Ramadorai, Tarun, 2008, What determines transaction costs in foreign exchange markets, International Journal of Finance and Economics 13, 14-25.

Reiss, Peter C., and Ingrid M. Werner, 1998, Does risk sharing motivate interdealer trading? Journal of Finance 53, 1657-1703.

Reiss, Peter C., and Ingrid M. Werner, 2004, Anonymity, adverse selection, and the sorting of interdealer trades, Review of Financial Studies 18, 599-636.

Reitz, Stefan, Markus Schmidt, and Mark Taylor, 2009, Financial intermediation and the role of price discrimination in a two-tier market, presented at the Fifth Annual Central Bank Workshop on the Microstructure of Financial Markets, Zurich, Switzerland, October 9, 2009.

Rime, Dagfinn, Lucio Sarno, and Elvira Sojli, 2009, Exchange-rate forecasting, order flow, and macroeconomic information, Journal of International Economics, forthcoming.

Theissen, Erik, 2003, Trader anonymity, price formation and liquidity, European Finance Review 7, 1-26.

Yao, Jian M., 1998, Market making in the interbank foreign exchange market, Working paper S-98-3, Stern School of Business, New York University. 


\section{Table I. Descriptive statistics, currency dealing at a small bank in Germany}

A. The table shows the complete USD/EUR trading activity of a small bank in Germany, except preferred customer trades, over the 87 trading days between July $11^{\text {th }}, 2001$ and November $9^{\text {th }}, 2001$.

\begin{tabular}{ccc|ccc} 
& \multirow{2}{*}{$\begin{array}{c}\text { All } \\
\text { Transactions }\end{array}$} & Interbank & \multicolumn{3}{|c}{ Customer } \\
\cline { 4 - 6 } & & & All & Financial & Commercial \\
\hline $\begin{array}{c}\text { Number of Transactions } \\
\text { (percent) }\end{array}$ & 3,609 & 1,919 & 1,690 & 171 & 1,519 \\
Of Which, Forward & $(100)$ & $(44)$ & $(56)$ & $(5)$ & $(42)$ \\
Value of trades $(\boldsymbol{€}$ mil.) & 646 & 114 & 532 & 60 & 472 \\
$\quad$ (percent) & 4,335 & 2,726 & 1,609 & 405 & 1,204 \\
$\quad \begin{array}{l}\text { Of Which, Forward } \\
\text { Mean Size (€ mil.) }\end{array}$ & $(100)$ & $(61)$ & $(39)$ & $(9)$ & $(28)$ \\
$\quad$ Mean Size, Forwards $(\boldsymbol{\epsilon}$ mil.) & 1.55 & 87 & 912 & 226 & 686 \\
\hline
\end{tabular}

B. The table shows the size distribution of all USD/EUR spot and forward transactions, except those for preferred customers, at a small bank in Germany over the period July 11 through November 9, 2001.

\begin{tabular}{lccc}
\hline & $\begin{array}{c}\text { Interbank } \\
\text { Trades }\end{array}$ & $\begin{array}{c}\text { Financial } \\
\text { Customer Trades }\end{array}$ & $\begin{array}{c}\text { Commercial } \\
\text { Customer Trades }\end{array}$ \\
\hline Number & 1,872 & 171 & 1,492 \\
Share & & & \\
$\quad$ Below $€ \mathbf{0 . 1}$ million & $7 \%$ & $15 \%$ & $54 \%$ \\
$€ \mathbf{0 . 1}-\mathbf{0 . 5}$ million & $9 \%$ & $26 \%$ & $32 \%$ \\
$€ \mathbf{0 . 5}-\mathbf{1 . 0}$ million & $7 \%$ & $14 \%$ & $5 \%$ \\
$€ \mathbf{1 . 0}-\mathbf{2 0}$ million & $77 \%$ & $44 \%$ & $8 \%$ \\
$€ \mathbf{2 0}$ million and above & $0 \%$ & $1 \%$ & $1 \%$ \\
\hline
\end{tabular}


Table II. Comparison of small bank studied here with larger banks studied in other papers.

The table shows the complete USD/EUR trading activity of a bank in Germany, except preferred customer trades, over the 87 trading days between July $11^{\text {th }}, 2001$ and November $9^{\text {th }}, 2001$. For comparison purposes we focus on statistics based exclusively on the small bank's spot trades.

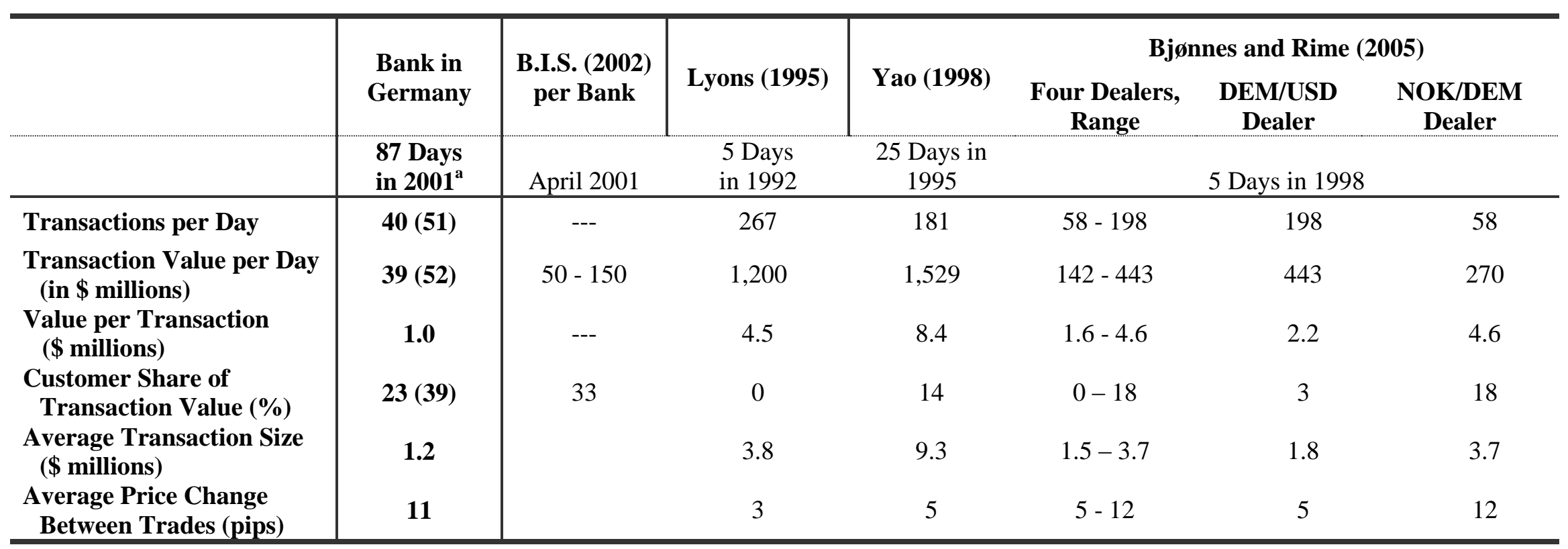

\footnotetext{
${ }^{\text {a }}$ Values in parentheses refer to the data set including outright-forward transactions.
} 


\section{Table III. Customer order flow and exchange rates}

Table shows results from OLS regressions of the exchange-rate level on a constant, a linear trend, and cumulative order flow, along with associated ECM coefficients. If incoming order flow of type $i$ is associated with a currency appreciation, the coefficient in the cointegration regression will be positive. Johansen tests with these three variables reject zero cointegrating relations and reject the existence of more than one cointegrating relation: regressions involving just one type of order flow are provided for comparison with earlier studies. The number of lags is calculated from the sample size (Newey-West automatic truncation lag selection). Order flow coefficients multiplied by $10^{3}$. Significance at the 1,5 , and 10 percent levels is indicated by $\ddagger, \uparrow$, and $*$, respectively.

\section{Standardized Coefficients}

\begin{tabular}{lccc}
\hline Cointegrating Relation & & \\
Financial-Customer Order Flow & 0.107 & $0.150 *$ & \\
Commercial-Customer Order Flow & $-0.370 \dagger$ & & $-0.301 \dagger$ \\
ECM for Exchange Rate Return & $-0.010 \dagger$ & $-0.051 \dagger$ & $-0.120 \dagger$ \\
\hline
\end{tabular}




\section{Table IV. Descriptive statistics for main regression variables}

Table provides descriptive statistics for key variables used to analyze the complete USD/EUR trading activity of a small bank in Germany, except preferred customer trades, during the period 11 July to 9 November, 2001. Price changes measured in pips; quantity traded $(Q)$ and inventories measured in millions of euros. There are 2,859 observations.

\begin{tabular}{lcccccccc}
\hline & $\boldsymbol{\Delta} \boldsymbol{P}_{\boldsymbol{t}}$ & $\mathbf{A B S}\left(\boldsymbol{\Delta} \boldsymbol{P}_{\boldsymbol{t}}\right)$ & $\boldsymbol{Q}_{\boldsymbol{t}}$ & $\mathbf{A B S}\left(\boldsymbol{Q}_{\boldsymbol{t}}\right)=\boldsymbol{V}_{\boldsymbol{t}}$ & Inventory & $\mid$ Inventory $\mid$ & $\boldsymbol{\Delta}$ Inventory & $\mid \boldsymbol{\Delta}$ Inventory $\mid$ \\
\cline { 2 - 8 } Mean & 0.2 & 10.78 & 0.02 & 1.08 & -23.8 & 24.0 & -0.02 & 1.25 \\
Median & 0.0 & 6.00 & 0.04 & 0.35 & -20.2 & 20.3 & -0.04 & 0.44 \\
Maximum & 99.7 & 99.7 & 76.4 & 76.4 & 32.8 & 84.0 & 76.32 & 76.43 \\
Minimum & -91.0 & 0.00 & -76.3 & 0.01 & -84.0 & 0.00 & -76.43 & 0.00 \\
Std. Dev. & 17.3 & 13.6 & 3.5 & 3.33 & 15.6 & 15.2 & 3.64 & 3.41 \\
Skewness & 0.07 & 2.09 & 0.6 & 13.0 & -0.19 & 0.32 & -0.38 & 12.0 \\
Kurtosis & 7.43 & 8.94 & 206 & 234 & 2.27 & 1.93 & 177 & 209 \\
\hline
\end{tabular}




\section{Table V. Huang and Stoll (1997) model}

We estimate this model: $\Delta P_{i t}=\frac{S}{2}\left(D_{t}-D_{t-1}\right)+\lambda \frac{S}{2} D_{t-1}-\theta \frac{S}{2} \Delta I_{i t}+e_{t}$.

$\Delta P_{i t}$ is the change in price between two successive customer trades measured in pips. $D_{\mathrm{t}}$ is +1 for buy-initiated trades and -1 for sell-initiated trades. $I_{i t}$ is the dealer's inventory, measured in EUR millions. These variables are interacted with dummy variables for trades with financial customers $(F C)$ and trades with commercial customers $(C C)$. They are also interacted with dummies for trade size: $L g .=\left\{\left|Q_{j t}\right| \in[1, \infty)\right\} ; M d .=\left\{\left|Q_{j t}\right| \in[0.5,1)\right\} ; \operatorname{Sm} .=\left\{\left|Q_{j t}\right| \in(0,0.5)\right\}$. Data include all incoming USD/EUR spot and forward trades of a small bank in Germany, except those with preferred customers, over the period July 11, 2001, through November 9, 2001. Estimation uses GMM and NeweyWest correction. Significance at 1, 5 and 10 percent levels indicated by $\ddagger, \uparrow$ and $*$, respectively. Constant term suppressed. Estimates of the baseline half spread are highlighted in bold.

\section{Baseline Regression}

Coefficient Std. Error

Half-Spread, $S / 2$

$S / 2 \times F C \times S m$.

$S / 2 \times F C \times M d$.

$S / 2 \times F C \times L g$.

$S / 2 \times C C \times S m$.

$S / 2 \times C C \times M d$.

$\mathrm{S} / 2 \times C C \times \mathrm{Lg}$.

$S / 2 \times I B \times S m .+M d$.

$S / 2 \times I B \times L g$.

\section{Adverse Selection}

$\lambda \times F C \times S m$.
$\lambda \times F C \times M d$.
$\lambda \times F C \times L g$.
$\lambda \times C C \times S m$.
$\lambda \times C C \times M d$.
$\lambda x C C \times L g$.
$\lambda \times I B \times S m .+M d$.
$\lambda \times I B \times L g$.

\section{Inventory}

$\theta \times F C \times S m$.

$\theta \times F C \times M d$.

$\theta x F C \times L g$.

$\theta \times C C \times S m$.

$\theta x C C \times M d$.

$\theta x C C \times L g$.

$\theta \times I B \times S m+M d$.

$\theta \times I B \times L g$.

$\begin{array}{ll}0.39 & 0.20 \\ 0.33 & 0.65 \\ 0.19 & 0.74 \\ 0.03 & 0.03 \\ 0.35^{*} & 0.19 \\ 0.51 & 0.81\end{array}$

0.10

$-1.00$

0.01

$-0.05$

0.08

0.01
Robustness Tests

$\begin{array}{ccc}\text { Inventory } & \text { Interbank } & \text { Spot Trades } \\ \text { Reset Daily } & \text { Trades Included } & \text { Only }\end{array}$

$10.54 \%$

13.48:

11.62\%
7.66 \%

$-5.46$

2.09

11.38:

16.12 \%

$5.34 \dagger$
$5.35 \dagger$

$4.20 \dagger$

$3.80 \dagger$

7.93\%

4.00*

4.93\%

11.98:

12.46\%

$5.44 \%$

$-0.97$

2.11+

0.32

0.46

0.27

$0.06+$

$0.39 \dagger$

0.51
$0.45 \dagger$

0.49

$0.65^{*}$

$0.12 \ddagger$

$0.35 \dagger$

0.34

0.03

$0.58 \dagger$

0.02

$-0.65$

$-0.01$

$-0.05$

0.06

$-0.02$

0.70

$-0.06$

Adjusted $\boldsymbol{R}^{2}$

0.33

0.25

0.48

$1.74 *$

$-1.14$

$0.20 \ddagger$

$0.69 \ddagger$

0.30

2,857

0.21

0.82

$-0.21$

0.01

0.05

0.07 


\section{Table VI. Madhavan-Smidt (1991) model}

We estimate this equation:

$$
\Delta P_{i t}=\alpha+\beta_{1} D_{t}+\beta_{2} D_{t-1}+\gamma_{1} I_{i t}+\gamma_{2} I_{i t-1}+\delta Q_{j t}+\varepsilon_{t}
$$

The dependent variable is the change in price between two successive incoming trades, measured in pips. $D_{\mathrm{t}}$ is an indicator variable picking up the direction of the deal, positive for purchases (at the ask) and negative for sales (at the bid); $I_{i t}$ is the dealer's inventory at time $t$, and $Q_{j t}$ is order flow measured in millions of euros. These variables are interacted with dummy variables for financial customers $(F C)$ and commercial customers $(C C)$. They are also interacted with dummies for trade size: $L g .=\left\{Q_{j t} \in[1, \infty)\right\} ; M d .=\left\{Q_{j t} \in[0.5,1)\right\} ; S m .=\left\{Q_{j t} \in(0,0.5)\right\}$. Data include all incoming customer USD/EUR spot and forward trades of a small bank in Germany, except those with preferred customers, over the period July 11, 2001, through November 9, 2001. Estimation uses GMM and Newey-West correction. Significance at 1,5 and 10 percent levels indicated by $\ddagger, \uparrow$ and $*$, respectively. Estimates of the (negative of the) baseline half spread are highlighted in bold.

\begin{tabular}{|c|c|c|c|c|c|}
\hline & \multicolumn{2}{|c|}{ Baseline Regression } & \multicolumn{3}{|c|}{ Robustness Tests } \\
\hline & Coefficient & Std. Error & $\begin{array}{c}\text { Inventory } \\
\text { Reset Daily }\end{array}$ & $\begin{array}{c}\text { Incl. Interbank } \\
\text { Trades }\end{array}$ & $\begin{array}{c}\text { Spot Trades } \\
\text { Only }\end{array}$ \\
\hline Constant & 0.14 & 0.49 & 0.03 & 0.028 & 0.33 \\
\hline \multicolumn{6}{|l|}{ Direction } \\
\hline$F C \times \operatorname{Sm} \times D_{t}$ & $13.58 \ddagger$ & 2.68 & $10.46 t$ & $6.94 \ddagger$ & $6.60 \ddagger$ \\
\hline$F C \times \operatorname{Sm} \times D_{t-1}$ & $-8.93 \div$ & 2.82 & $-6.62 \ddagger$ & $-4.05 \%$ & -3.44 \\
\hline$F C \times M d . x D_{t}$ & 3.18 & 2.58 & 3.92 & 2.98 & 1.18 \\
\hline$F C \times M d . x D_{t-1}$ & -3.14 & 3.08 & -2.97 & -1.82 & -3.18 \\
\hline$F C \times L g . x D_{t}$ & 3.87 & 1.94 & 2.40 & $5.20 t$ & 1.97 \\
\hline$F C \times L g . x D_{t-1}$ & -2.58 & 1.97 & $-3.62 *$ & -1.62 & -1.08 \\
\hline$C C \times \operatorname{Sm} . x D_{t}$ & $13.30 \ddagger$ & 0.64 & $13.33 t$ & $11.87 \ddagger$ & $11.26 t$ \\
\hline$C C \times S m . x D_{t-1}$ & $-13.24 \%$ & 0.62 & $-12.68 t$ & $-10.43+$ & $-9.08 \%$ \\
\hline$C C \times M d . x D_{t}$ & $10.82 \ddagger$ & 1.49 & $12.62 t$ & $12.34 \hbar$ & $13.55 t$ \\
\hline$C C \times M d . x D_{t-1}$ & $-5.73 \ddagger$ & 2.15 & $-7.20 \%$ & $-7.97 \div$ & $-5.29 \ddagger$ \\
\hline$C C \times L g . x D_{t}$ & 1.43 & 1.51 & $4.68 \dagger$ & $5.80 \%$ & $6.56 \div$ \\
\hline$C C \times L g . \times D_{t-1}$ & 0.59 & 1.81 & -2.06 & $-3.52 \%$ & -4.25 \\
\hline$I B \times M d .+\operatorname{Sm} . x D_{t}$ & & & & -0.96 & \\
\hline$I B \times M d .+S m . x D_{t-1}$ & & & & -0.01 & \\
\hline$I B \times L g . x D_{t}$ & & & & $2.22 \ddagger$ & \\
\hline$I B \times L g . x D_{t-1}$ & & & & $-0.88 *$ & \\
\hline \multicolumn{6}{|l|}{ Inventory } \\
\hline$F C \times I_{i t}$ & -0.58 & 0.50 & -0.46 & -0.32 & 0.28 \\
\hline$F C \times I_{i t-1}$ & 0.65 & 0.51 & 0.37 & 0.30 & -0.28 \\
\hline$C C \times I_{i t}$ & 0.47 & 0.42 & $1.05 \dagger$ & 0.65 & -0.13 \\
\hline$C C x I_{i t-1}$ & -0.51 & 0.42 & $-1.09 \ddagger$ & -0.64 & 0.14 \\
\hline$I B \times I_{i t}$ & & & & 0.01 & \\
\hline$I B \times I_{i t-1}$ & & & & 0.00 & \\
\hline \multicolumn{6}{|l|}{ Trade size } \\
\hline$F C \times Q_{j t}$ & -0.60 & 0.52 & 0.12 & -0.41 & 0.10 \\
\hline$C C \times Q_{j t}$ & 0.52 & 0.43 & $0.77 *$ & 0.53 & -0.13 \\
\hline$I B \times Q_{j t}$ & & & & -0.18 & \\
\hline Adjusted $R^{2}$ & \multicolumn{2}{|c|}{0.32} & 0.33 & 0.33 & 0.35 \\
\hline Observations & \multicolumn{2}{|c|}{1,644} & 1,651 & 2,857 & 1,131 \\
\hline
\end{tabular}




\section{Table VII. Glosten-Harris (1988) Model}

We estimate this model: $\quad \Delta P_{t}=c_{0}\left(D_{t}-D_{t-1}\right)+c_{1}\left(D_{t} V_{t}-D_{t-1} V_{t-1}\right)+z D_{t} V_{t}+\varepsilon_{t}$.

The dependent variable is the change in price between two successive incoming trades, measured in pips. $D_{\mathrm{t}}$ is an indicator variable picking up the direction of the deal, positive for purchases (at the ask) and negative for sales (at the bid); $V_{j t}$ is the absolute value of order flow measured in millions of euros. These variables are interacted with dummy variables for financial customers $(F C)$ and commercial customers $(C C)$ and other banks $(I B)$. Data include all incoming regular-sized customer USD/EUR spot and forward trades of a small bank in Germany, except those with preferred customers, over the period July 11, 2001, through November 9, 2001. Estimation uses GMM with Newey-West standard errors. Significance at 1, 5 and 10 percent levels indicated by $\ddagger, \uparrow$ and $*$, respectively.

\begin{tabular}{|c|c|c|c|c|}
\hline & \multicolumn{2}{|c|}{ Baseline Regression } & \multicolumn{2}{|c|}{ Robustness Tests } \\
\hline & Coefficient & Std. Error & $\begin{array}{l}\text { Interbank Trades } \\
\text { Included }\end{array}$ & Spot Trades Only \\
\hline \multicolumn{4}{|l|}{ Transitory spread component $c_{0}$} & $7.43 t$ \\
\hline$\left(F C_{t} * D_{t}-F C_{t-1} * D_{t-1}\right)$ & $5.12 \dagger$ & 1.17 & $4.92 \dagger$ & $5.64 \dagger$ \\
\hline$\left(I B_{t} * D_{t}-I B_{t-1} * D_{t-1}\right)$ & & & 0.39 & \\
\hline \multicolumn{5}{|l|}{ Volume coefficient $c_{1}$} \\
\hline$\left(C C_{t} * V_{j t} * D_{t}-C C_{t-1} * V_{j t-1} * D_{t-1}\right)$ & $-0.32 \ddagger$ & 0.12 & $-0.29 \ddagger$ & $-0.71 \dagger$ \\
\hline$\left(F C_{t} * V_{j t} * D_{t}-F C_{t-1} * V_{j t-1} * D_{t-1}\right)$ & $-0.46 \dagger$ & 0.13 & $-0.33 \%$ & $-0.15^{*}$ \\
\hline$\left(I B_{t} * V_{j t} * D_{t}-I B_{t-1} * V_{j t-1} * D_{t-1}\right)$ & & & 0.23 & \\
\hline \multicolumn{5}{|l|}{ Adverse-selection component $z$} \\
\hline$C C^{*} D_{t}^{*} V_{j t}$ & -0.18 & 0.16 & -0.22 & 0.33 \\
\hline$F C^{*} D_{t} * V_{j t}$ & 0.24 & 0.23 & 0.15 & 0.33 \\
\hline$I B * D_{t} * V_{j t}$ & & & 0.19 & \\
\hline Adjusted $R^{2}$ & \multicolumn{2}{|c|}{0.33} & 0.24 & 0.06 \\
\hline Observations & \multicolumn{2}{|c|}{1,645} & 2,853 & 1,129 \\
\hline
\end{tabular}




\section{Table VIII. Probit regression of choice of outgoing interbank trades}

We estimate this equation, $\operatorname{Prob}\left(\right.$ Trade $\left._{t}=I B^{\text {out }}\right)=P\left(F C_{t-1}, C C_{t-1}, S D F C_{t-1}, S D C C_{t-1}, 10\right.$ mio $\left._{t-1},\left|I_{i t}\right|, I_{i t}{ }^{2},\left|Q_{j t}\right|\right)$, as a probit regression. Incoming (outgoing) interbank trades are coded $0(1) . F C_{t-1}$ is a dummy coded one if the previous counterparty was a financial customer, $C C_{t-1}$ and $I B_{t-1}$ are defined similarly for commercial customers and other banks. $S D F C$ (SDCC) is a dummy coded one if the current dealer trade has the same direction as the previous financial-customer (commercial-customer) trade. $10 \mathrm{mio}_{t-1}$ is a dummy coded one if the size of the previous transaction was $€ 10$ million or larger. $I$ represents inventories, in millions of euros; $\left|Q_{j t}\right|$ represents the absolute size of the current deal, measured in EUR millions; Significance at the 1,5 and 10 percent levels indicated by $\ddagger$, $\dagger$ and $*$, respectively.

\begin{tabular}{|c|c|c|c|c|c|}
\hline & \multicolumn{2}{|c|}{ Baseline Regressions } & \multicolumn{3}{|c|}{ Robustness Tests } \\
\hline & $\begin{array}{c}\text { No } \\
\text { Direction }\end{array}$ & $\begin{array}{c}\text { With } \\
\text { Direction }\end{array}$ & $\begin{array}{c}\text { Inventory } \\
\text { Reset Daily }\end{array}$ & $\begin{array}{c}\text { Interbank } \\
\text { Trades In- } \\
\text { cluded }\end{array}$ & $\begin{array}{c}\text { Spot Trades } \\
\text { Only }\end{array}$ \\
\hline$F C_{t-1}$ & -0.115 & $-0.441 \ddagger$ & $-0.441+$ & $-0.588 \ddagger$ & $-0.408 \dagger$ \\
\hline$C C_{t-1}$ & $-0.537 \dagger$ & $-0.754 \div$ & $-0.748 \div$ & $-0.901 \ddagger$ & $-0.621 \div$ \\
\hline SameDirection FC & & $1.221 \dagger$ & 1.219 & $1.221 \%$ & $1.108+$ \\
\hline Same Direction CC & & $0.928 \ddagger$ & $0.930 \ddagger$ & $0.928 \ddagger$ & $1.065 \ddagger$ \\
\hline 10 mio $_{t-1}$ & $0.668+$ & $0.736 t$ & $0.719 \ddagger$ & $0.740 \%$ & $0.450 \ddagger$ \\
\hline$I B_{t-1}$ & & & & $-0.223 t$ & \\
\hline$\left|I_{i t}\right|$ & $-5.28 \mathrm{E}-3$ & -0.005 & $0.031 \ddagger$ & $-4.4 \mathrm{E}-3$ & $-5.03 E-3$ \\
\hline$I_{i t}^{2}$ & $9.19 \mathrm{E}-5$ & $8.40 \mathrm{E}-5$ & $-0.001 \dagger$ & $7.55 \mathrm{E}-5$ & $9.76 \mathrm{E}-5$ \\
\hline$\left|Q_{i t}\right|$ & $0.024 \$$ & $0.025 t$ & $0.029 \ddagger$ & $0.024 \$$ & 0.014 \\
\hline Constant & $-0.740 \ddagger$ & $-0.741 \ddagger$ & -0.879 & $-0.600 \ddagger$ & $-0.938 \ddagger$ \\
\hline McFadden's $R^{2}$ & 0.038 & 0.069 & 0.072 & 0.072 & 0.084 \\
\hline Observations & 3,534 & 3,534 & 3,534 & 3,534 & 2,894 \\
\hline
\end{tabular}


Figure 1: Intraday distribution of trades

The charts below show the average number of trades during each five-minute period of the trading day. Data come from a small bank in Germany and include all USD/EUR spot and forward trades during four months in 2001.

Figure 1A: Financial-customer trades

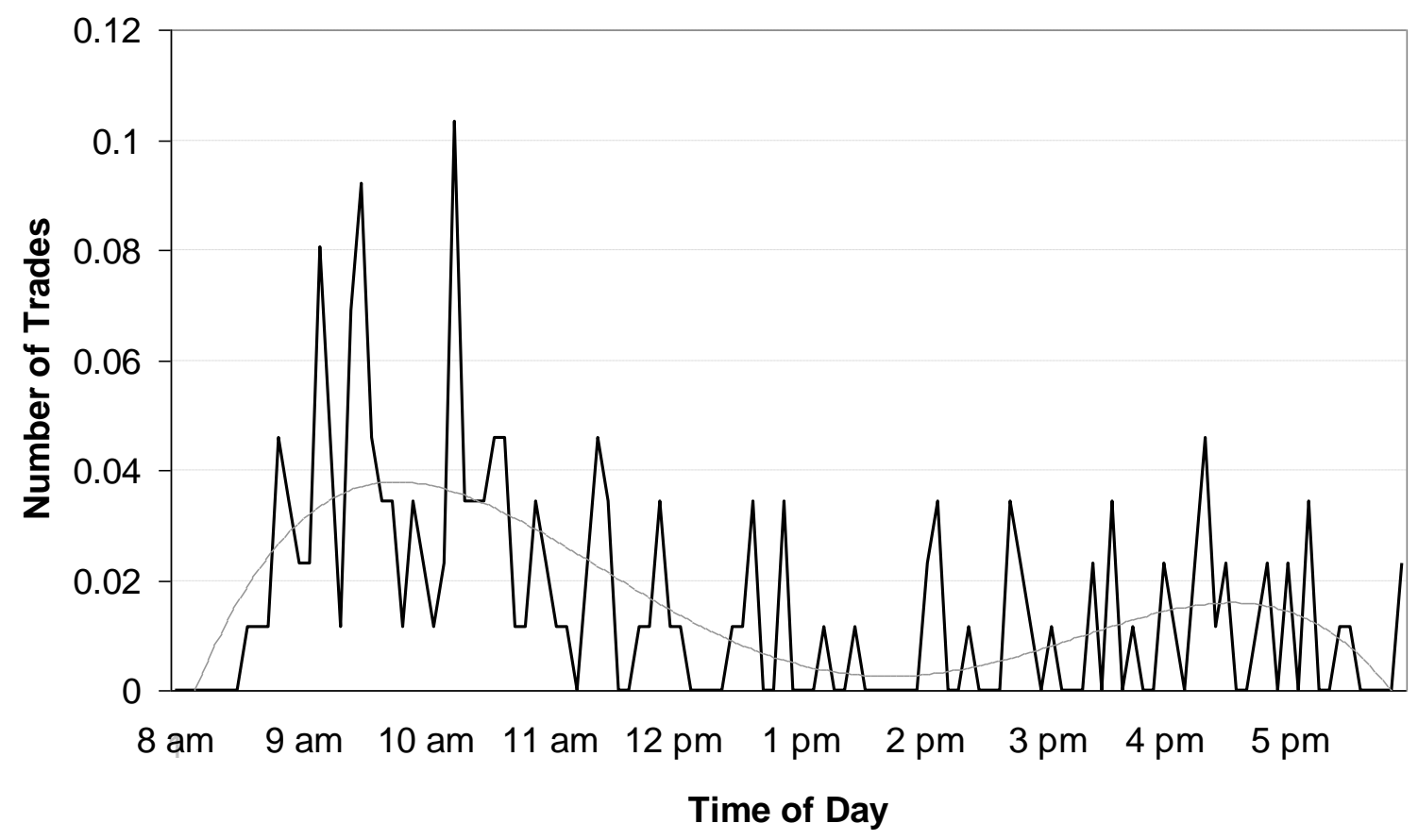

Figure 1B: Commercial-customer trades

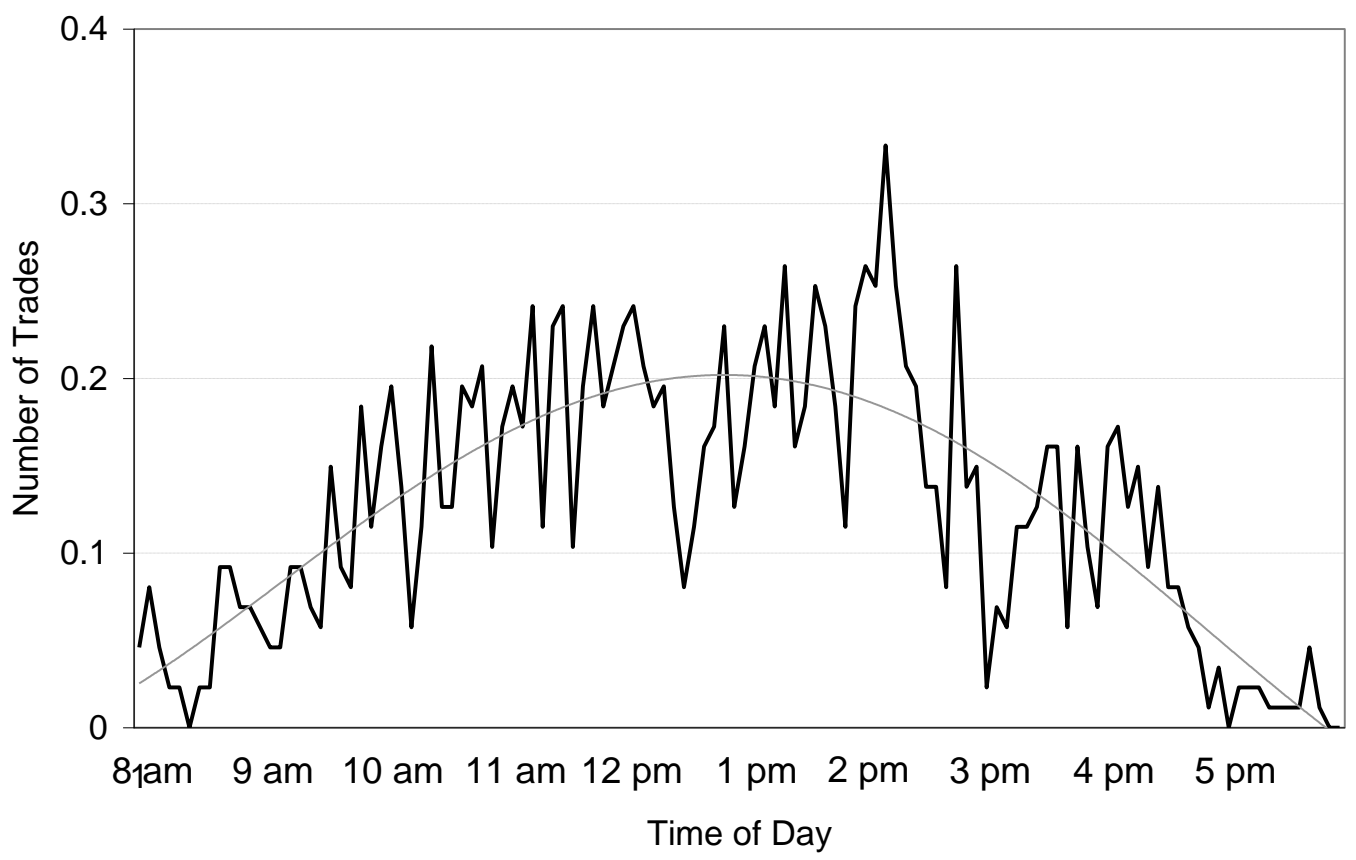

